\title{
Interplay Between Calcium and AMPK Signaling in Human Cytomegalovirus Infection
}

\author{
Diana M. Dunn and Joshua Munger* \\ Department of Biochemistry and Biophysics, School of Medicine and Dentistry, University of Rochester, Rochester, NY, \\ United States
}

\section{OPEN ACCESS}

Edited by:

Michael Nevels,

University of St Andrews,

United Kingdom

Reviewed by:

Giorgio Gribaudo,

University of Turin, Italy

Scott Terhune,

Medical College of Wisconsin,

United States

*Correspondence:

Joshua Munger

josh.munger@rochester.edu

Specialty section:

This article was submitted to Virus and Host,

a section of the journal

Frontiers in Cellular and Infection

Microbiology

Received: 30 April 2020

Accepted: 23 June 2020

Published: 29 July 2020

Citation:

Dunn DM and Munger J (2020) Interplay Between Calcium and AMPK Signaling in Human Cytomegalovirus Infection

Front. Cell. Infect. Microbiol. 10:384 doi: 10.3389/fcimb.2020.00384
Calcium signaling and the AMP-activated protein kinase (AMPK) signaling networks broadly regulate numerous aspects of cell biology. Human Cytomegalovirus (HCMV) infection has been found to actively manipulate the calcium-AMPK signaling axis to support infection. Many HCMV genes have been linked to modulating calcium signaling, and HCMV infection has been found to be reliant on calcium signaling and AMPK activation. Here, we focus on the cell biology of calcium and AMPK signaling and what is currently known about how HCMV modulates these pathways to support HCMV infection and potentially contribute to oncomodulation.

Keywords: cytomegalovirus, HCMV, calcium signaling, AMPK, cancer, oncomodulation

\section{INTRODUCTION}

Human Cytomegalovirus (HCMV) infection is a prevalent opportunistic pathogen, infecting $\sim 60-90 \%$ of the global population (Pass, 2001). It remains latent in most individuals, but causes significant morbidity in immunoimmature or immunocompromised hosts including neonates, transplant recipients, AIDS patients, and cancer patients undergoing immunosuppressive therapies (Pass, 2001; Kuo et al., 2008; El-Cheikh et al., 2013; Tay et al., 2013; Teh et al., 2013). Evidence of HCMV infection and its contributions to mortality in cancer patient populations has increased over time (Nguyen et al., 2001; Boeckh, 2011; Wang et al., 2011; Tay et al., 2013; Jaillette et al., 2016; Rådestad et al., 2018), partially due to inadequate anti-HCMV therapeutics. Approximately $0.6 \%$ of babies in developing countries are HCMV seropositive, and $10 \%$ of infected infants suffer from microcephaly, hearing and vision loss, mental impairments and even death, making HCMV infection one of the leading causes of birth defects (Schottstedt et al., 2010; Swanson and Schleiss, 2013). Current therapies often have poor bioavailability, exhibit long-term toxicity in afflicted patients and can often lead to the development of drug resistance due to the prolonged treatment regimens required to eliminate lytic infection (Weisenthal et al., 1989; Flores-Aguilar et al., 1993; Goodrich et al., 1993; Andrei et al., 2008).

HCMV can spread through mucosal membranes, via blood, through the placenta and breast milk from mother to child, or through saliva and sexual secretions. Primary infection and viral replication occur in a wide variety of cell types including fibroblasts, epithelial cells, endothelial cells, mononuclear cells, and neural progenitor cells (Sison et al., 2019). Viral latency is established in hematopoietic stem cells, as these cells differentiate into myeloid derived macrophages and dendritic cells, they become more permissive to reactivation of the virus (Hahn et al., 1998; O'Connor and Murphy, 2012; Forte et al., 2020).

HCMV is a betaherpes virus containing a large double-stranded DNA genome of about 230,000 base pairs (Schottstedt et al., 2010), encoding for a largely unknown proteomic potential 
(Stern-Ginossar et al., 2012). The regulation and function of these gene products by both the virus and host cell shape the viral environment and the potential to successfully produce viral progeny. It is known that the upstream calcium-calmodulin signaling cascade protein, CaMKK, and its downstream target, AMP-activated protein kinase (AMPK), both play a critical role in HCMV-mediated glycolytic activation and viral replication (McArdle et al., 2011, 2012). These two overlapping pathways were proven to be crucial for activation of glycolysis during infection, but both impact cellular function beyond metabolic regulation. In this review we will explore the contributions of calcium signaling and AMPK signaling to HCMV infection and how these pathways contribute to oncogenesis.

\section{HCMV AND CANCER}

HCMV infection commonly causes acute infection in cancer patients undergoing immunosuppressive therapies for the treatment of leukemia, lymphoma, and myeloma (Kuo et al., 2008; El-Cheikh et al., 2013; Tay et al., 2013; Teh et al., 2013). Although controversial, it has also been associated with certain brain cancers including malignant glioma and medulloblastoma (Cobbs et al., 2002, 2007; Baryawno et al., 2011; Soroceanu et al., 2011; Ranganathan et al., 2012; Rahman et al., 2019). Due to the immunosuppressive nature of the treatments used to fight various cancers, these cancer patient populations are highly susceptible to HCMV infection. Not only are they more likely to be affected by acute infection or reactivation of latent infection, but HCMV encodes for gene products with oncogenic potential that could promote cancer formation and further contribute to cancer progression.

HCMV is not considered to be a directly transforming virus, yet many of its gene products are capable of driving specific oncogenic phenotypes. This property, known as oncomodulation, suggests that HCMV infection may play a yet unknown role in oncogenesis by transforming the cellular environment into one more conducive to tumor formation. HCMV infection and its oncogenic potential has been reviewed in detail by many [see Michaelis et al. (2009), Herbein (2018), Nauclér et al. (2019)]. In brief, HCMV infection institutes many host cell changes that mirror the hallmarks of cancer including: manipulation of cellular energy metabolism, promoting the cell cycle, and evading growth suppression, avoiding the immune response while promoting inflammation, cellular immortalization, activating invasion, motility, and angiogenesis, genomic changes, and manipulation of the apoptotic response. HCMV prevalence, indicated by the presence of its nucleic acids or proteins, has been associated with multiple cancer types, including breast, colon, prostate, liver, salivary, brain, and soft tissue cancers (Hanahan and Weinberg, 2011; Nauclér et al., 2019). A recent study has taken a deep look into the transcriptome of 2,658 cancers from 38 tumor types. HCMV was associated at low levels with most of the tumor types, although further validation is needed to better understand if HCMV infection is actually associated with all of the presented tumor types or if it was a contaminate due to its frequency across the samples tested (Zapatka et al., 2020). Additionally, some groups have shown that normal colorectal and breast tissues, adjacent to HCMV-infected tumors, often remain uninfected, further suggesting a specific role for HCMV in the tumor microenvironment (Taher et al., 2013, 2014; Bai et al., 2016).

\section{CALCIUM SIGNALING: CAMKK}

Calcium signaling plays a pivotal role during HCMV infection. In this section we will describe calcium signaling orchestrated by a family of serine/threonine kinases and the downstream consequences of calcium signaling (Figure 1). We will also explore the viral proteins and HCMV-induced cellular proteins that contribute to aberrant calcium signaling.

Calcium-calmodulin $\left(\mathrm{Ca}^{2+}{ }_{-} \mathrm{CaM}\right)$ dependent protein kinase kinase (CaMKK) is encoded by two genes, CAMKK1 and CAMKK2 resulting in the expression of CaMKK $\alpha$ (or CaMKK1) and CaMKK $\beta$ (or CaMKK2) proteins, originally studied in rat brain (Edelman et al., 1996). CaMKK exists in an autoinhibited state in the presence of basal cellular calcium levels. Calcium flux through the plasma membrane or release of internal stores into the cytoplasm activates the small messenger protein, calmodulin, which in turn releases autoinhibition and activates CaMKK kinase activity toward downstream $\mathrm{Ca}^{2+}$-CaM activated proteins, CaMKI (Lee and Edelman, 1994), and CamKIV (Tokumitsu et al., 1994). Regulation of CaMKK via other kinases also plays a role in the $\mathrm{Ca}^{2+}-\mathrm{CaM}$ signaling cascade. The phosphorylation status of CaMKK can determine the fate of $\mathrm{Ca}^{2+}$-CaM binding. Specifically, serine- 458 phosphorylation facilitated by cAMP-dependent protein kinase (PKA), within the CaM binding domain of CaMKK, will block CaM from binding thus inhibiting CaMKK activity (Matsushita and Nairn, 1999; Davare et al., 2004). More recently, it was also shown that multi-phosphorylation of CaMKK $\beta$ by cyclin-dependent kinase 5 (CDK5) and glycogen synthase kinase 3 (GSK3) results in decreased kinase activity and decreased CaMKK $\beta$ protein stability (Green et al., 2011). Alternatively, autophosphorylation at threonine- 482 in the regulatory domain of CaMKK $\beta$ increases its activity by decreasing its autoinhibition, independent of $\mathrm{Ca}^{2+}$ CaM binding (Tokumitsu et al., 2001, 2011).

CaMKK activity plays a role in gene transcription through regulation of its downstream CaMK proteins, as well as its activity toward AMPK (Woods et al., 2005) (discussed below). It also interacts with protein kinase B (PKB/Akt) (Yano et al., 1998), via phosphorylation of threonine-308 and serine-473 (Gocher et al., 2017), resulting in an antiapoptotic effect through upregulation of pro-survival pathways. CaMKK activity has also been linked to apoptosis through phosphorylation of CaMKK $\beta$ by death associated protein kinase (DAPK), whose activity toward CaMKK $\beta$ reduces CaMKK autophosphorylation and elicits a proapoptotic response. The authors suggest this mechanism could occur through reduction of CaMKK phosphorylation of the downstream effector, Akt (Schumacher et al., 2004). These studies show that not only does CaMKK play a critical role in direct $\mathrm{Ca}^{2+}$-CaM signaling through CaMKI and CaMKIV, 


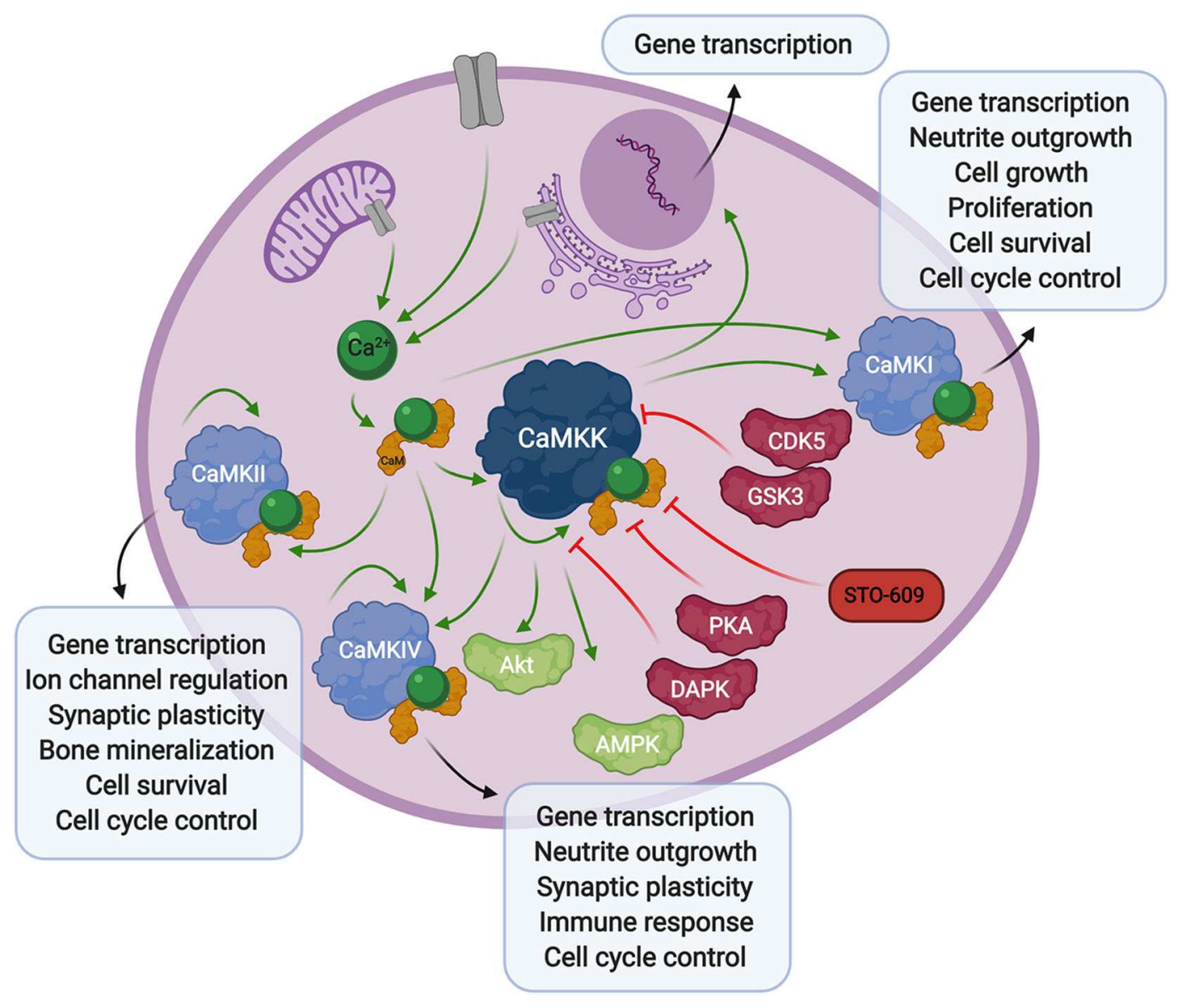

FIGURE 1 | Overview of calcium signaling. Calcium release from the extracellular space or intracellular compartments into the cytosol activates calmodulin, which in turn binds to CaMKK and CaMK proteins. Phosphorylation of CaM-binding proteins via autophosphorylation or upstream kinases further activates, or in some cases inhibits their activity toward downstream signaling proteins and transcription factors. The CaMKK inhibitor, STO-609, can also stall these downstream processes.

but it is able to influence the apoptotic pathway in a more direct manner.

Expression of CaMKK has been identified in an array of rat tissues, most notably in the brain, and CaMKK $\beta$ is also found at lower levels in the thymus, spleen, lung, and testis (Tokumitsu et al., 1995; Anderson et al., 1998). In human tissue, CaMKK is again predominantly found in the brain (Ohmstede et al., 1989), but is widely detected across multiple tissues at the RNA and protein levels, including enrichment of CaMKK $\alpha$ in endocrine, digestive tissue, prostate, bone marrow, lymphoid tissues, and enrichment of CaMKK $\beta$ in lung and heart muscle (Uhlén et al., 2015). Additionally, CaMKK $\beta$ encodes for distinct isoforms, most notably, CaMKK $\beta 1$ and CaMKK $\beta 2$, which exhibit differential activities and expression patterns in normal vs. human tumor tissue and cell lines. Most notably, normal human brain tissues express transcripts for CaMKK $\beta 1$ and CaMKK $\beta 2$, while brain tumors express smaller CaMKK $\beta 1$ transcript variants at high levels. Preferential expression of these smaller transcripts was also observed in established brain tumor cell lines (Hsu et al., 2001). It was also shown that exon 14 of CaMKK $\beta$ is required for its autophosphorylation, independent of $\mathrm{Ca}^{2+}{ }_{-} \mathrm{CaM}$ binding, but that $\mathrm{Ca}^{2+}{ }_{-} \mathrm{CaM}$ binding is required for its downstream activity toward CaMK proteins (Hsu et al., 2001). Due to the nature of CaMKK $\beta$ expression in normal and cancerous brain tissues, its activity could also play a role during HCMV infection. The impact of HCMV infection on the structural development of the brain is discussed in more detail below.

\section{Calcium Signaling: CaMKI, CaMKII, CaMKKIV}

CaMKI exists in four isoforms, CaMKI $\alpha$, CaMKI $\beta /$ Pnck, CaMKI $\gamma / \mathrm{CLICK} 3$, and CaMKI $\delta / \mathrm{CKLiK}$, each encoded by a separate gene (CAMK1, PNCK, CAMK1G, and CAMKID). All contain similar autoinhibitory domains, which require release via phosphorylation by CaMKK and $\mathrm{Ca}^{2+}{ }_{-} \mathrm{CaM}$ binding for full activation (Soderling and Stull, 2001; Senga et al., 2015). It is the most ubiquitously expressed group of CaMK proteins, and the isoforms can be found at various levels in all tissues (Picciotto et al., 1995), but are most highly expressed in brain tissues (Nairn and Greengard, 1987; Kamata et al., 2007). Substrates of CaMKI are generally involved in gene transcription (Swulius and Waxham, 2008). Two widely studied CaMKI targets are 
extracellular signal-regulated kinase (ERK) and cAMP response element-binding protein (CREB). Predominantly CaMKI $\alpha$ and CaMKI $\beta$ activities toward CREB activate neuronal transcription and stimulates neurite outgrowth (Sheng et al., 1991; Yan et al., 2016). CaMKI is responsible for the induction of ERK transcriptional activity, which results in the stimulation of cell growth, proliferation, and cell survival pathways (Schmitt et al., 2004, 2005). There are several other reports of CaMKI activity toward central transcriptional regulators, each having similar outcomes on cell survival and growth with response to calcium signaling.

CaMKII is activated by CaM-binding and autophosphorylation activity. It is responsible for the regulation of many downstream targets involved in ion channel regulation, synaptic plasticity, and gene transcription (Swulius and Waxham, 2008). CaMKII is unique in that it exists as a multimeric dodecamer in the cell, as opposed to the other CaM-binding proteins, which exist in monomeric forms. There are four isoforms, CaMKII $\alpha$, CaMKII $\beta$, CaMKII $\gamma$, and CaMKIIS (encoded by CAMK2A, CAMK2B,CAMK2G, and $C A M K 2 D)$. Each varies slightly in size and contains a variable linker region which can produce splicing isoforms. The isoforms are differentially expressed in multiple tissues throughout the human body (Brzozowski and Skelding, 2019). CaMKII $\alpha$ and $\beta$ are primarily expressed in brain tissue, while $\gamma$ and $\delta$ are more ubiquitous across tissue types. The multimeric structure of CaMKII is thought to contribute to regulation of synaptic transmission, as CaMKII $\alpha, \beta$, and $\gamma$ are commonly associated with synaptic vesicles (Ouimet et al., 1984; Takamori et al., 2006; Wang, 2008). Autophosphorylation of threonine-286 is essential for synaptic plasticity, learning, and memory in the brain (Giese et al., 1998). CaMKII also plays an important role in $\mathrm{Ca}^{2+}$ channel activity in heart muscles, where it phosphorylates and tethers itself to channel component, $\alpha 1 c$, thereby tightly regulating $\mathrm{Ca}^{2+}$ spikes in the heart (Hudmon et al., 2005; Maier and Bers, 2007). During osteoblast differentiation, CaMKII is stimulated by $\mathrm{Ca}^{2+}$ influx, and phosphorylates downstream proteins: cAMP-response element (CRE) and serum response element (SRE). CaMKII further facilitates transcriptional changes, often associated with osteoblast differentiation, thus stimulating bone mineralization (Shin et al., 2008). More recently, CaMKII has been shown to be important in the regulation of cell death in both neurons during ischemia via an unknown mechanism (Rostas et al., 2017) and osteoblasts through activation of multiple upstream pathways including ER stress, MAPK activation and mTOR signaling (Liu et al., 2018). CaMKII is a physiologically versatile and extensively studied CaMK protein, which is required for the regulation of multiple cellular functions crucial for normal cellular function and functions important for HCMV infection.

Both CaMKII and CaMKI have also been implicated as important mediators of cell cycle progression. Expression of a kinase-dead CaMKI mutant elicits a stall in the G1 cell cycle phase, while inhibition with CaMKII inhibitors has a negative impact on the G2/M and metaphase-anaphase transitions of the cell cycle (Skelding et al., 2011). The role of CaMKII in microtubule dynamics by regulation of centrosome duplication
(Matsumoto and Maller, 2002), may also impact AMPKmediated modulation of cytoskeletal and microtubule dynamics. Additionally, CaMKII has been linked to mitotic instability (Mones et al., 2014), often associated with cancers.

CaMKIV is activated via CaMKK phosphorylation, but also exhibits autophosphorylation capabilities. These phosphorylation events, in combination with CaM-binding, result in full activation of downstream target proteins. It is encoded by one gene, CAMK4, which produces two or more splice variants (Brzozowski and Skelding, 2019). CaMKIV is primarily responsible for an array of gene transcription events and is expressed in the brain at high levels (Ohmstede et al., 1989) but can be found in other cell types and tissues such as immune cells and reproductive organs (Skelding et al., 2011). Transcriptional activity of downstream CaMKIV targets has also been implicated in neurite outgrowth, the immune response and cell cycle control. CaMKIV can activate CREB activity, causing a $\mathrm{Ca}^{2+}$ dependent regulation of transcription (Enslen et al., 1994), but to a lesser extent than observed with CaMKI stimulation in most studies (Enslen et al., 1995). CaMIV activation of CREB has been linked to synaptic plasticity (Bleier and Toliver, 2017), has been found to be required for fear memory (Wei et al., 2002), and has been linked to hematopoietic stem cell homeostasis (Kitsos et al., 2005). Cell cycle control through regulation of microtubule dynamics has also been linked to CaMKIV activity (Melander Gradin et al., 1997). Finally, as reviewed here (Racioppi and Means, 2008), CaMIV plays a pivotal role in immune cells and the inflammatory response, leading to the possibility that the status of CaMIV in the cell could modify the permissiveness of a cell to HCMV infection and tumor formation or invasion. In general, CaMKI, CaMKKII, and CaMKIV activities are similar, but their distinct differences could potentially impact the state of a cell during HCMV infection and lead to oncomodulation of the cellular environment.

\section{CALCIUM SIGNALING: SUBSTRATE-SPECIFIC CAM-BINDING KINASES}

There are three characterized $\mathrm{Ca}^{2+}-\mathrm{CaM}$ binding proteins that phosphorylate only a single known substrate and are referred to as substrate-specific calcium signaling molecules. CaMKIII, also known as elongation factor 2 kinase (eEF2K), solely requires CaM-binding for its activation (Swulius and Waxham, 2008). It inhibits protein translation by phosphorylating elongation factor 2 (eEF2), thus dissociating it from the ribosome in skin, lung, gastrointestinal, pancreas, reproductive, bone, and lymphoid tissues (Nairn and Palfrey, 1987; Uhlén et al., 2015). Another $\mathrm{Ca}^{2+}$-CaM activated kinase, MLCK, acts in muscle contraction (Kamm and Stull, 1985; Word et al., 1994), and intracellular transport in muscle tissue (Mochida et al., 1994), through myosin activation. Finally, Phosphorylase kinase is the only non-monomeric substrate-specific CaM-binding protein, consisting of a complex tetrameric structure, that is ubiquitously expressed across numerous tissue types, but is most commonly found in skeletal muscle and liver tissues (Swulius and Waxham, 
2008). It acts toward glycogen metabolism via phosphorylation of glycogen phosphorylase, thereby regulating energy needed for muscle contractions (Kishimoto et al., 1977; Cohen et al., 1980; Picton et al., 1981) and maintenance of blood-glucose levels (Conaglen et al., 1985). A role for the substrate-specific CaMbinding proteins during HCMV infection or in cancer has yet to be elucidated.

\section{HCMV-MEDIATED MODULATION OF CALCIUM SIGNALING}

Several HCMV genes have been linked to regulation of calcium signaling. Many of these are associated with apoptotic functions, including US21, UL37, and US28. US21 is a viroporin which encodes for a $\mathrm{Ca}^{2+}$-permeable channel responsible for decreasing intracellular calcium stores and protects against the intrinsic apoptotic response induced by various drugs (Luganini et al., 2018). UL37 encodes for the viral mitochondria-localized inhibitor of apoptosis (vMIA), which is an inhibitor of the proapoptotic protein, Bax, thus promoting cell survival (Goldmacher et al., 1999; Arnoult et al., 2004; Poncet et al., 2004). Additionally, UL37 localizes to both the mitochondrial membrane and the endoplasmic reticulum (ER), where it causes dysregulation in the membrane structure of the mitochondria, and leads to release of calcium stores into the cytosol from the ER (McCormick et al., 2003; Sharon-Friling et al., 2006).

US28, on the other hand, promotes apoptosis through caspase activation, presumably to promote HCMV-associated disease progression in specific cell types (Pleskoff et al., 2005). It is a viral $G$ protein-coupled receptor responsible for internalizing chemokines (Gao and Murphy, 1994). This internalization of chemokines is accompanied by a release of intracellular calcium (Gao and Murphy, 1994; Vieira et al., 1998). Another study examined the effects of US28 expression in a variety of cell types permissive to HCMV infection including smooth muscle, endothelial, and glioblastomas cells. US28 was found to drive phospholipase C- $\beta$ (PLC- $\beta$ ) which in turn drives intracellular calcium release in all cell types with the exception of glioblastoma cells, in which the authors suggest this could play a role in latent infection. PLC- $\beta$ signaling was dependent on chemokine response in most cells but could also occur in the absence of chemokines in smooth muscle cells (Miller et al., 2012).

Another viral protein involved in chemokine response, UL146, encodes for a viral chemokine (vCXCL1) which acts as an agonist for human chemokines (CXCR1 and CXCR2) responsible for intracellular calcium release. This chemokine response also has implications in neutrophil recruitment, which then act as passive carriers of the virus. These data suggest that calcium signaling plays a role in viral dissemination through the host (Penfold et al., 1999; Wang et al., 2003). Finally, it is suggested that HCMV binds epidermal growth factor receptor (EGFR) as part of the internalization of the virus, which also causes the mobilization of intracellular calcium, a response that is known to occur with native ligand binding of EGF to EGFR (Wang et al., 2003). Additionally, EGF-mediated calcium release has been linked to cell migration and angiogenesis in glial cells, which again could contribute to HCMV infection in certain brain cancer patients (Bryant et al., 2004). Collectively, these data suggest that multiple HCMV gene products significantly modulate calcium signaling to impact cell growth, apoptosis, and inflammatory responses.

\section{CONTRIBUTIONS OF CALCIUM SIGNALING TO INFECTION}

Activated calcium signaling could contribute to infection in a variety of ways. CaMKK activity plays a crucial role in transcriptional regulation of the cell, largely through downstream activation of CaMKI, CaMKII, and CaMKIV. Activation of these kinases also impacts cellular trafficking, protein translation, apoptosis, metabolism, ion channel regulation, intracellular transport, cell cycle control, and immune cell function, all of which are crucial for HCMV infection. Although this group of proteins is generally enriched in the brain, these proteins are found ubiquitously throughout the human body. Naturally, since the calcium signaling proteins are found at higher levels in the brain, they have been best characterized predominantly in this context. Although lower in other tissues, calcium signaling can still be very important to normal cellular function, and there is evidence to its activity being hijacked by HCMV infection to create a more permissive environment for viral replication. Many proteins are known to be induced by stressful events such as infection, including CaMKK $\alpha$ (McArdle et al., 2011). Induction of CaMKK upon HCMV infection contributes to HCMV-mediated glycolytic activation. Treatment of cells with STO-609, a potent inhibitor of CaMKK, attenuates viral infection and inhibits HCMV-mediated glycolytic activation (McArdle et al., 2011).

As discussed, calcium signaling plays a critical role in the regulation of neuronal cell growth and development. HCMV infection can impact this system in neonates, causing microcephaly and developmental delays at birth. A recent study has shown that HCMV infection impacts the ability of organoid tissues to organize, develop, and differentiate properly. In this study, the authors show that HCMV infected neural progenitor cells lose calcium channel signaling and lose their ability to respond to changes in calcium levels (Sison et al., 2019). The altered state of infected cells overall disrupted structural development of cortical organoids (Sison et al., 2019), which could contribute to the formation of improperly functioning synapses and overall brain mass loss during development leading to HCMV-associated brain impairments in infants.

\section{HCMV INDUCTION OF CALCIUM SIGNALING COULD BE IMPLICATED IN TUMORIGENESIS}

Many of the same calcium signaling pathways crucial to HCMV infection could also contribute to the oncogenic potential of the cell. Calcium signaling has been the target of many anticancer studies due to its importance in cellular processes involved in cancer cell survival and progression. These studies included 
the use of CaMKK inhibitor STO-609, CaMKII inhibitor KN$62 / \mathrm{KN}-93$, Berbamine, a CaMKII $\gamma$ inhibitor, and peptides designed to target CaMKII, all of which are reviewed here (Brzozowski and Skelding, 2019). In general, use of these calcium pathway inhibitors decreased proliferation, migration and invasion, induced apoptosis, or slowed cell cycle progression in multiple cancer cell and tumor types including prostate, medulloblastoma, glioma, lung, breast, and $\mathrm{T}$ cell lymphoma, as well as others (Brzozowski and Skelding, 2019). Additionally, multiple studies have suggested that US28 can also promote proliferation and angiogenesis by modulation of inflammatory factors, resulting in enhanced tumorigeneses upon infection of intestinal epithelial cells (Bongers et al., 2010), glioblastoma cells (Slinger et al., 2010), and tumorigenic NIH3T3 cells in mouse models (Maussang et al., 2009; Slinger et al., 2010). Primary glioblastoma tumors from patients were also examined for the presence of US28, which correlated with STAT3 phosphorylation, IL-6 production, higher levels of tumor proliferation, and poorer patient outcomes (Slinger et al., 2010). Finally, CaMKK $\beta$ has also been implicated in promoting prostate cancer progression through the upregulation of lipogenesis, a phenotype also associated with HCMV infection (Penfold et al., 2018).

\section{AMPK SIGNALING}

Similar to CaMKK, AMPK activity has been linked to high HCMV viral titers and HCMV-mediated glycolytic activation. It is also a known tumor suppressor but exhibits some oncogenic phenotypes under specific conditions. In this section we will describe the AMPK structure and function in normal cells (Figure 2), then describe the role it plays in HCMV infection, and how this could contribute to HCMV-associated oncomodulation.

AMPK is a serine/threonine kinase that plays a central role in metabolic stress signaling by responding to low levels of ATP in the cell. The AMPK protein is a heterotrimeric complex consisting of a catalytic subunit, $\alpha$, and two regulatory subunits, $\beta$ and $\gamma$. There are several protein isoforms of each subunit, $\alpha 1, \alpha 2, \beta 1, \beta 2, \gamma 1, \gamma 2$, and $\gamma 3$, each encoded by their own gene, PRKAA1, PRKAA2, PRKAB1, PRKAB2, PRKAG1, $P R K A G 2$, and PRKAG3, resulting in 12 possible AMPK complex formations (Ross et al., 2016b). Canonical AMPK activation relies on two signals. The first is the binding of AMP to its regulatory $\gamma$ domain, which causes a conformational change in the protein heterotrimeric complex to expose threonine172 , thereby promoting its phosphorylation and inhibiting its dephosphorylation by protein phosphatases (Hardie et al., 2016). The secondary phosphorylation step is facilitated by upstream kinases, Liver Kinase B1 (LKB1) (Woods et al., 2003) or calcium signaling protein, CaMKK (Woods et al., 2005), to promote full activation of AMPK. CaMKK $\beta$ is known to stimulate AMPK more than CaMKKo (Fujiwara et al., 2016), and can stimulate AMPK activity independently of the cellular AMP/ATP ratios if intracellular calcium levels are elevated in adipocytes (Gormand et al., 2011) and other cell types. It has also been reported that ADP binding to the $\gamma$ subunit can promote conformational changes making the protein more susceptible to
Thr-172 phosphorylation, but to a much lesser extent than AMP binding (Gowans et al., 2013).

The AMPK subunit isoforms exhibit some tissue specificity that can translate into functional differences. In general, the $\mathrm{AMPK} \alpha 1$ catalytic subunit is ubiquitously expressed, while the $\mathrm{AMPK} \alpha 2$ catalytic subunit is preferentially expressed at higher levels in the liver, skeletal, and cardiac muscles. Additionally, the $\alpha 2$ subunit is not expressed in hematopoietic cells (Stapleton et al., 1996; Foretz et al., 2010a; Wang et al., 2016). This tissue specificity plays a functional role in the skeletal system, where $\alpha 2$ promotes osteogenesis at a higher level than $\alpha 1$ (Wang et al., 2016). Whole mouse knockout of either AMPK catalytic subunit is viable with minor defects at the molecular level (Viollet et al., 2003; Fu et al., 2013a,b). Most notably, $\alpha 1$ knockout mice present with severe anemia due to lack of any AMPK activity in blood cells (Foretz et al., 2010a). Simultaneous knockout of both the AMPK $\alpha 1$ and AMPK $\alpha 2$ subunits, results in embryonic lethality around day 10 in mice (Viollet et al., 2009). Double knockout of the AMPK $\alpha$ subunits, has been successfully preformed in cultured mouse embryonic fibroblast (MEF) cells (Lee et al., 2020). This is not surprising, since AMPK plays an important role in development (Carey et al., 2014; Kaufman and Brown, 2016), but in mature cells it is possible that both catalytic subunits play similar roles, or can at least compensate for one another when they are both present in that cell type. The AMPK $\beta$ regulatory subunits are ubiquitously expressed, with a preference for $\beta 2$ expression in skeletal muscle (Mobbs et al., 2015). Differential roles for the $\beta$ subunits have not been explored in detail. Finally, it is not well-defined whether the AMPK $\gamma$ regulatory subunits exhibit tissue specificity, but $\gamma 1$ is found at higher abundances than $\gamma 2$ or $\gamma 3$ in skeletal and cardiac muscles (Pinter et al., 2013). The $\gamma$ subunit isoforms have also been shown to differentially impact the rate of AMPK activity, where $\gamma 2$ containing AMPK complexes activate more rapidly than $\gamma 1$ or $\gamma 3$ containing AMPK complexes. Additionally, the $\gamma$ subunits exhibit differential affinities for AMP and ADP which mediate their ability to activate the protein (Ross et al., 2016a; Willows et al., 2017). Again, many of the studies involving AMPK subunit tissue localization have focused on cardiac and skeletal tissues, but this does not preclude AMPK activity from being important for other tissue specific functions in the body, such as the brain where calcium signaling is best characterized.

As mentioned above, AMPK is a stress regulated kinase, which responds to low levels of ATP in the cell, with the overall goal of producing more ATP and rebalancing cellular energy. AMPK inhibits cell growth through inactivation of mTOR signaling (Gwinn et al., 2008; Kalender et al., 2010), and controls autophagy through manipulation of ULK1 (Kim et al., 2011). Its activity is both directly associated with metabolic enzyme modification as well as through more long-term transcriptional regulation of metabolic processes, cell growth, differentiation, immune response, and apoptosis (McGee et al., 2008). Direct glycolytic substrates of AMPK include acetyl-CoA carboxylase (ACC), whose phosphorylation by AMPK inhibits a key step in fatty acid biosynthesis (Park et al., 2002). AMPK also phosphorylates the high capacity glucose transporter, GLUT4, which signals for its translocation to the plasma membrane 


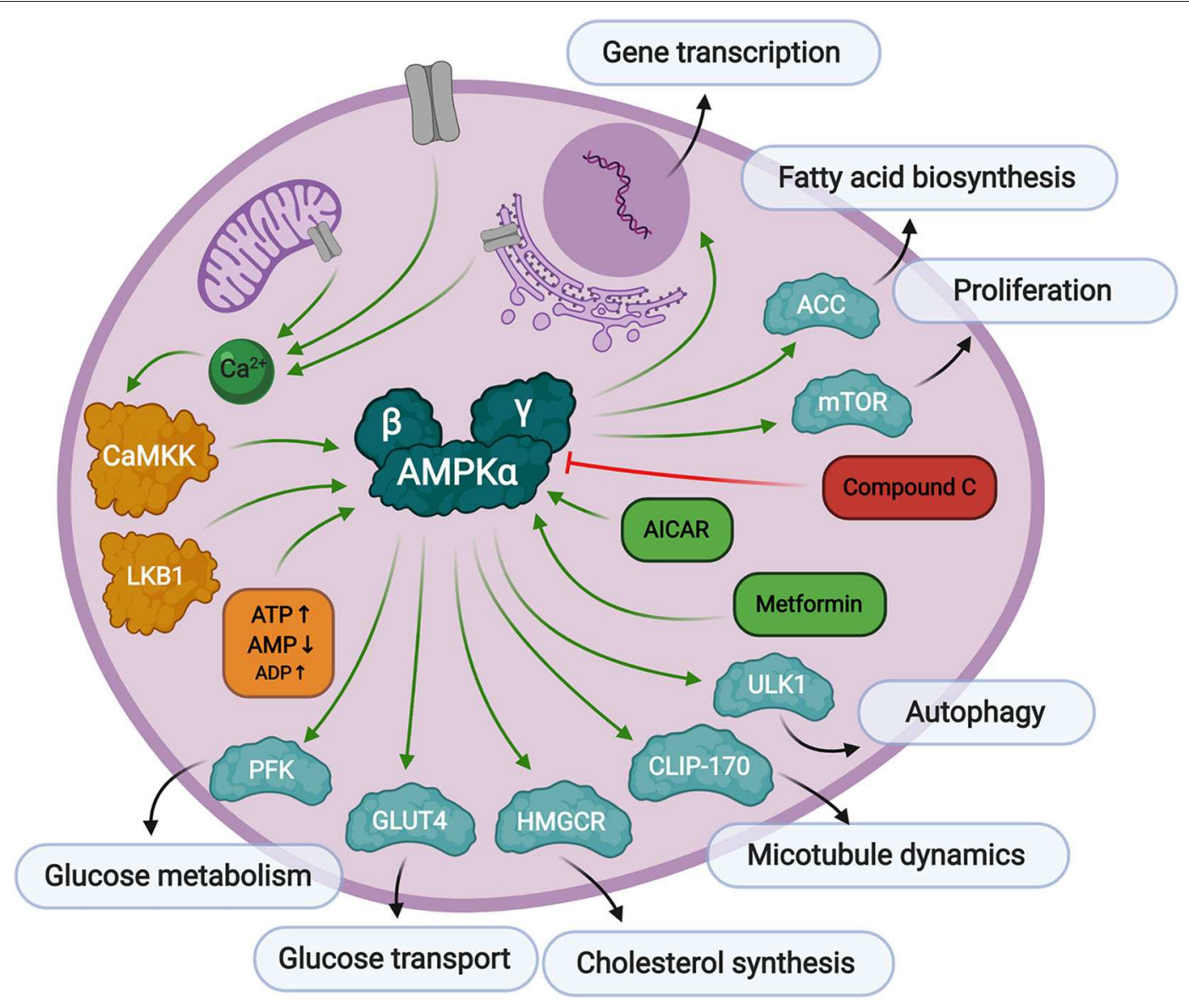

FIGURE 2 | Overview of AMPK signaling. AMPK responds to low levels of ATP in the cell. First, AMP binds to the AMPK $\gamma$ regulatory subunit causing a conformational change exposing threonine-172 in the AMPK $\alpha$ catalytic subunit. Then, Thr-172 is phosphorylated by upstream kinases, CaMKK, or LKB1, fully activating AMPK kinase activity toward substrates responsible for preserving cellular energy. AMPK can be activated by AICAR or metformin treatment, and inhibited by Compound C.

(Kurth-Kraczek et al., 1999) thus increasing glucose uptake into the cell. Glycolytic flux is also regulated through AMPK phosphorylation of 6-phosphofructo-2-kinase (PFK-2) which controls the levels of 2,6-bisphopsphate, which in turn regulates the activity of the key glycolytic enzyme, 6-phosphofructo-1kinase (PFK-1) (Marsin et al., 2000). Another role of AMPK is its regulation of cytoskeleton dynamics. As mentioned before, AMPK can be regulated by calcium signaling, which is also a major contributor to microtubule and centrosome structure. AMPK directly phosphorylates CLIP-170, causing dissociation of the growing end of microtubules (Nakano et al., 2010). AMPK has also been implicated in neuronal polarization (Williams et al., 2011). Though not an exhaustive list, it is clear that many of the verified AMPK phospho-targets are generally involved in the preservation and production of cellular energy.

\section{AMPK ASSOCIATIONS WITH HCMV INFECTION}

Many AMPK targets play a critical role in HCMV infection, including mTOR (Rodríguez-Sánchez et al., 2019), ACC (Spencer et al., 2011), and GLUT4 (Yu et al., 2011). AMPK activity has also been directly linked to HCMV infection. One study preformed an siRNA screen of the cellular kinome, assessing HCMV replication as a readout. In this study, several AMPK subunits, the AMPK activator CaMKK, and several downstream AMPK targets were identified as modulators of HCMV infection. Furthermore, inhibition of AMPK by its inhibitor, Compound C (CC), dramatically changed HCMV-mediated induction of metabolite pools (Terry et al., 2012). Data from in vitro AMPK activity assays revealed that HCMV infection activates AMPK. Further, during HCMV infection, AMPK $\alpha$ accumulates and its phosphorylation increases. AMPK activity is necessary for HCMV-mediated activation of glycolysis and production of high viral titers, a process that can be halted by the addition of CC (McArdle et al., 2012). While these studies revealed that AMPK activity is necessary for productive HCMV infection, excessive AMPK activity can also have a detrimental impact on viral production. Use of AMPK activators, AICAR or metformin, also contributes to a loss of viral replication (Kudchodkar et al., 2007; Terry et al., 2012; Li et al., 2017). It has been suggested that timing of AMPK activation plays a critical role in successful 
HCMV replication. It is possible that AMPK activity is important at a specific time during infection, and less important, or even detrimental at alternate times post infection. It is also possible that the studies utilizing AMPK inhibitors or activators, are observing off-target effects of the drugs themselves. Initially CC was reported as a specific ATP competitive inhibitor through an in vitro assay (Hsich et al., 2001). Since then it has been reported that CC can target many more kinases including CaMKK (Bain et al., 2007; Jester et al., 2010). Although metformin is associated with AMPK activation, it does not directly interact with the AMPK protein. Instead it inhibits mitochondrial respiratory chain complex 1, which in turn increases the ratio of AMP to ATP, thus indirectly activating AMPK (Owen et al., 2000). Work has also shown that AMPK does not always play a role in metformin associated phenotypes, as metformin-associated genes remain unchanged between normal, AMPK $\alpha$ knockout, and LKB1 knockout hepatocytes (Foretz et al., 2010b). This suggests a role for metformin that is independent of AMPK activity, which could potentially affect HCMV infection by an unknown mechanism. Excessive AMPK activation could also have a negative impact on its inhibition of certain AMPK targets, such as ACC. AMPK activity toward ACC results in the inhibition of fatty acid biosynthesis, which is detrimental to HCMV infection (Spencer et al., 2011). A similar phenomenon could be occurring when AMPK phosphorylates 3-hydroxy-3methylglutaryl CoA reductase (HMGCR), which is responsible for cholesterol synthesis, another important cellular process that is key to HCMV growth (Potena et al., 2004; Shenk and Alwine, 2014). It is possible that the virus is able to manipulate ACC and HMGCR activity irrespective of its phosphorylation by AMPK during normal infection but cannot compensate for activated AMPK during AICAR or metformin treatment. Finally, specific combinations of AMPK subunit isoforms may also play a role in AMPK's substrate specificity and ultimately impact HCMV infection but have yet to be fully interrogated.

\section{AMPK IMPLICATIONS IN CANCER}

There are reports indicating mutational changes of the AMPK subunits in cancer. First, some evidence suggests that AMPK $\alpha 1$ acts as an oncogene, while $\alpha 2$ may act as a tumor suppressor. The AMPK activator, LKB1, is encoded by the gene STK11, which is mutated or deleted in many cancers. Most commonly, in lung carcinomas carrying STK11 alterations, the AMPK $\alpha 1$ gene (PRKAA1) is often amplified, while mutations in the PRKAA2 gene occur less frequently (Monteverde et al., 2015). In support of this, double knockout of AMPK $\alpha 1$ and $\alpha 2$ in MEF cells transformed with H-RasV12 fail to grow tumors in immunodeficient mice (Laderoute et al., 2006) while transformed MEFS with $\alpha 2$ knockout exhibit a growth advantage in tumors. In contrast, $\alpha 1$ knockouts do not develop tumors and even exhibit compensation with total levels of $\alpha 2$ (Phoenix et al., 2012). These data suggest distinct and separate roles for the AMPK catalytic subunits in cancer, which cannot be rescued with compensation of the alternate isoform. The AMPK $\beta 1$ subunit is mutated in $<4 \%$ of cancers, in contrast to the $\beta 2$ subunit, which is aberrantly expressed in upwards of $10 \%$ of cancers, with its expression commonly amplified (Monteverde et al., 2015). It has also been reported that the $\alpha 1$ subunit requires $\beta 2$ for its stability during overexpression, which could implicate the correlation between the amplification of these two subunits in cancer (Ross et al., 2016b). There are few reported mutations of the AMPK $\gamma$ subunit isoforms in cancer. It is possible that their roles change upon mutation or amplification of the $\alpha$ and $\beta$ subunits.

Many canonical AMPK activities lend themselves to AMPK acting as a tumor suppressor, and therefore loss of expression would promote tumorigenesis (Shackelford and Shaw, 2009). Recent work has shown that treatment of colorectal cancer cells and breast cancer cells and tissues with a novel AMPK activator (FNDs) induces apoptosis and cancer cell death (Kenlan et al., 2017; Johnson et al., 2019). But there is also evidence that AMPK is critical for the maintenance of established tumors and could therefore be targeted for anti-cancer therapies in certain contexts. As mentioned, reports suggest that the AMPK $\alpha 1$ gene acts as an oncogene and the $\alpha 2$ gene acts as a tumor suppressor. $\mathrm{AMPK} \alpha 1$ activation via CaMKK $\beta$ is reported to promote cancer cell survival and protection against genotoxic stress induced by etoposide treatment, while AMPK $\alpha 2$ did not exhibit this protective effect (Vara-Ciruelos et al., 2018). These data suggest that inhibition of $A M P K$ in $A M P K \alpha 1$ rich tumors may be a more effective treatment. Additionally, tumors requiring a higher metabolic rate may also be disadvantaged by AMPK inhibition and supported by AMPK activation. Studies have shown that tumors require AMPK's metabolic functions to maintain tumor cell viability in the face of energetic stressors (Jeon and Hay, 2012). The same oncogenically-associated characteristics of AMPK activity may also apply to cells infected by HCMV. These data also highlight a prominent role for the AMPK subunits during stressful cellular events requiring functional cell survival and metabolic processes (Jeon and Hay, 2015).

\section{INTERSECTION OF CALCIUM AND AMPK SIGNALING DURING HCMV INFECTION}

As evidenced above, both calcium and AMPK play central roles in the cellular stress response and intersect with each other in the cytosol (Figure 3). Calcium signaling is heavily regulated by viral genes involved in apoptosis and the chemokine response. Upon calcium mobilization from the extracellular space or from within organelles such as the mitochondria or endoplasmic reticulum, CaMKK starts the calcium signaling cascade. This is when AMPK can be activated, in addition to other cellular signals coming from LKB1. Together, CaMKK and AMPK are responsible for immediate phosphorylation signals of target proteins and longterm activation of transcription factors involved in countless cellular processes involved in the promotion of viral replication. Inhibition of either CaMKK by STO-609 or AMPK by CC, as well as activation of AMPK by metformin or AICAR, results in diminished viral replication. These processes are delicately balanced by HCMV infection in order to promote successful release of viral progeny. 


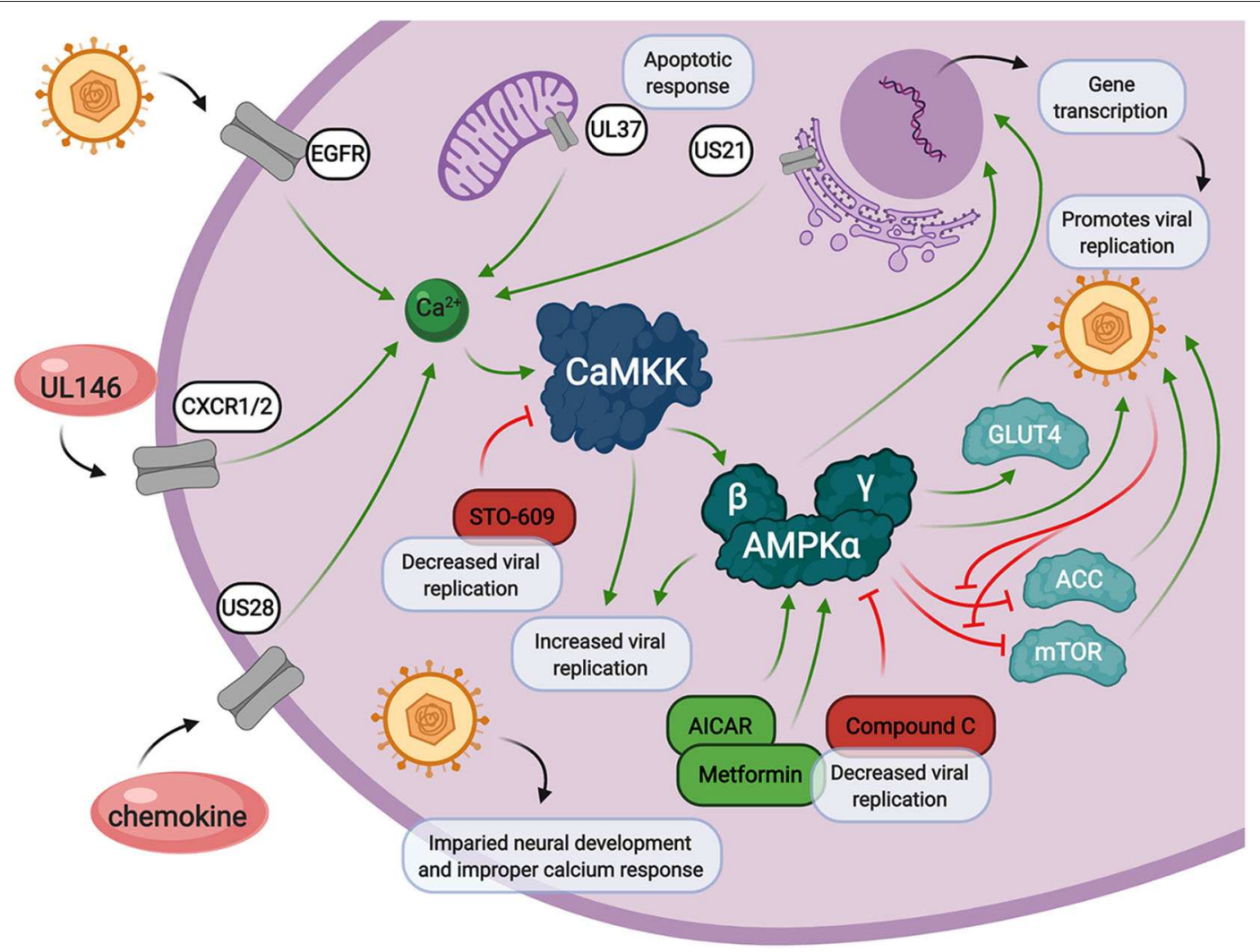

FIGURE 3 | Calcium and AMPK signaling during HCMV infection. Calcium signaling contributes to increased intracellular calcium release through HCMV encoded genes, UL146, US28, UL37, and US21, and through viral entry via epidermal growth factor receptor (EGFR). HCMV infection also induces the expression of CaMKK and AMPK, both of which are crucial for viral replication through multiple cellular signals. HCMV infection also impacts neural cell development which is associated with loss of proper calcium response. Inhibition of CaMKK by STO-609 inhibits HMCV viral replication. AMPK inhibition by Compound C, or activation by metformin or AICAR, also results in a decrease in HCMV viral replication.

\section{CONCLUSIONS AND PERSPECTIVES}

Cellular stress often affects cell proliferation, apoptosis, cell cycle, and the immune response, so it is not unreasonable to think that, in some way, each pathway contributes to modulating host cell homeostasis and HCMV infection. HCMV has adapted to carefully control calcium signaling through many of its gene products, US28, US21, UL37, and UL146, as well as through the manipulation of calcium signaling protein, CaMKK. HCMV also acts downstream of CaMKK, on AMPK, to further manipulate host cell transcription and more specifically, host cell metabolism for the benefit of the virus. There is significant overlap in the downstream consequences of calcium and AMPK signaling, yet the downstream functional targets of these pathways that control HCMV infection are largely unknown. Identifying them and elucidating their contributions to infection will greatly increase our understanding of how these host pathways contribute to infection and could potentially identify targets for therapeutic intervention.

Studies focusing strictly on calcium signaling in the brain and AMPK activity in cardiac or skeletal tissues have opened the door to many unanswered questions about how these signaling pathways contribute to cellular function and various pathologies in other tissues. Many of the proteins discussed above are ubiquitously expressed in all cell types and perform basal functions in normal cells. HCMV infection occurs in a broad range of host cells, and both calcium and AMPK signaling play a significant role during infection. One major question that remains largely unanswered, is how do these signaling pathways contribute to latent HCMV infection? It has been suggested that a lack of calcium signaling, for instance, in the brain may contribute to low lytic infection and inadvertently promote latency in these cells (Miller et al., 2012). Calcium signaling has also been implicated in neutrophil recruitment (Penfold et al., 1999; Wang et al., 2003), which could play a role in the lytic to latent transition. Additionally, $\mathrm{AMPK} \alpha 1$ is expressed in hematopoietic cells while AMPK $\alpha 2$ is not (Stapleton et al., 1996; Foretz et al., 2010a; Wang et al., 2016). As major reservoirs for latent virus, studies with hematopoietic and myeloid progenitor cells (Schottstedt et al., 2010; Murray et al., 2018), may highlight an isoform specific role of the AMPK catalytic subunits in HCMV infection or latency. 
Lastly, HCMV infection has been associated with numerous types of cancers as discussed above. Many cancers rely on AMPK and calcium signals to promote tumor formation and survival. Although many of these associations are not fully understood, there is evidence that HCMV infection promotes oncomodulation, and this could be mediated by viral modulation of calcium and AMPK signaling. For example, the prevalence of the HCMV gene US28, which is responsible for intracellular calcium mobility (Gao and Murphy, 1994; Vieira et al., 1998), is associated with patient glioblastomas and poor cancer prognosis (Slinger et al., 2010). It remains unknown whether calcium or AMPK signaling are viable targets for anti-HCMV or anticancer therapeutics. Based on our current knowledge, and the known overlap between the pathway signaling molecules, there is a possibility that specific CaM-binding proteins, or specific AMPK subunits could be successfully targeted. Future research will further our understanding of the functional interactions between HCMV and these important cellular pathways and will shed light on the potential for targeting these pathways to limit $\mathrm{HCMV}$-associated pathogenesis.

\section{REFERENCES}

Anderson, K. A., Means, R. L., Huang, Q. H., Kemp, B. E., Goldstein, E. G., Selbert, M. A., et al. (1998). Components of a calmodulin-dependent protein kinase cascade. Molecular cloning, functional characterization and cellular localization of $\mathrm{Ca}^{2+} /$ calmodulin-dependent protein kinase kinase beta. J. Biol. Chem. 273, 31880-31889. doi: 10.1074/jbc.273.48.31880

Andrei, G., de Clercq, E., and Snoeck, R. (2008). Novel inhibitors of human CMV. Curr. Opin. Investig. Drugs 9, 132-145.

Arnoult, D., Bartle, L. M., Skaletskaya, A., Poncet, D., Zamzami, N., Park, P. U., et al. (2004). Cytomegalovirus cell death suppressor vMIA blocks Bax- but not Bak-mediated apoptosis by binding and sequestering Bax at mitochondria. Proc. Natl. Acad. Sci. U. S. A. 101, 7988-7993. doi: 10.1073/pnas.0401897101

Bai, B., Wang, X., Chen, E., and Zhu, H. (2016). Human cytomegalovirus infection and colorectal cancer risk: a meta-analysis. Oncotarget 7, 76735-76742. doi: 10.18632/oncotarget.12523

Bain, J., Plater, L., Elliott, M., Shpiro, N., Hastie, C. J., McLauchlan, H., et al. (2007). The selectivity of protein kinase inhibitors: a further update. Biochem. J. 408, 297-315. doi: 10.1042/BJ20070797

Baryawno, N., Rahbar, A., Wolmer-Solberg, N., Taher, C., Odeberg, J., Darabi, A., et al. (2011). Detection of human cytomegalovirus in medulloblastomas reveals a potential therapeutic target. J. Clin. Invest. 121, 4043-4055. doi: 10.1172/JCI57147

Bleier, J., and Toliver, A. (2017). Exploring the role of CaMKIV in homeostatic plasticity. J. Neurosci. 37, 11520-11522. doi: 10.1523/JNEUROSCI.2599-17.2017

Boeckh, M. (2011). Complications, diagnosis, management, and prevention of CMV infections: current and future. Hematol. Am. Soc. Hematol. Educ. Program 2011, 305-309. doi: 10.1182/asheducation-2011.1.305

Bongers, G., Maussang, D., Muniz, L. R., Noriega, V. M., Fraile-Ramos, A., Barker, N., et al. (2010). The cytomegalovirus-encoded chemokine receptor US28 promotes intestinal neoplasia in transgenic mice. J. Clin. Invest. 120, 3969-3978. doi: 10.1172/JCI42563

Bryant, J. A., Finn, R. S., Slamon, D. J., Cloughesy, T. F., and Charles, A. C. (2004). EGF activates intracellular and intercellular calcium signaling by distinct pathways in tumor cells. Cancer Biol. Ther. 3, 1243-1249. doi: $10.4161 /$ cbt.3.12.1233

Brzozowski, J. S., and Skelding, K. A. (2019). The multi-functional calcium/calmodulin stimulated protein kinase (CaMK) family: emerging targets for anti-cancer therapeutic intervention. Pharmaceuticals 12:8. doi: $10.3390 /$ ph12010008

\section{AUTHOR CONTRIBUTIONS}

DD wrote the manuscript and created the figures. DD and JM contributed to the content and editing of this manuscript. All authors contributed to the article and approved the submitted version.

\section{FUNDING}

DD was supported by a postdoctoral fellowship (133137-PF-19038-01-MPC) from the American Cancer Society. The work was also supported by NIH grants AI127370 and AI150698 to JM and by a Research Scholar Grant from the American Cancer Society (grant RSG-15-049-01-MPC).

\section{ACKNOWLEDGMENTS}

We would like to thank Xenia L. Schafer for proofreading and editing this manuscript.

Carey, E. A., Albers, R. E., Doliboa, S. R., Hughes, M., Wyatt, C. N., Natale, D. R., et al. (2014). AMPK knockdown in placental trophoblast cells results in altered morphology and function. Stem Cells Dev. 23, 2921-2930. doi: $10.1089 /$ scd. 2014.0092

Cobbs, C. S., Harkins, L., Samanta, M., Gillespie, G. Y., Bharara, S., King, P. H., et al. (2002). Human cytomegalovirus infection and expression in human malignant glioma. Cancer Res. 62, 3347-3350.

Cobbs, C. S., Soroceanu, L., Denham, S., Zhang, W., Britt, W. J., Pieper, R., et al. (2007). Human cytomegalovirus induces cellular tyrosine kinase signaling and promotes glioma cell invasiveness. J. Neurooncol. 85, 271-280. doi: 10.1007/s11060-007-9423-2

Cohen, P., Klee, C. B., Picton, C., and Shenolikar, S. (1980). Calcium control of muscle phosphorylase kinase through the combined action of calmodulin and troponin. Ann. N. Y. Acad. Sci. 356, 151-161. doi: 10.1111/j.1749-6632.1980.tb29608.x

Conaglen, J. C., Williams, A. B., Malthus, R. S., Glover, D., and Sneyd, J. G. (1985). Blood glucose homeostasis in rats with a deficiency of liver phosphorylase kinase. Am J. Physiol. 248, E44-E50. doi: 10.1152/ajpendo.1985.248.1.E44

Davare, M. A., Saneyoshi, T., Guire, E. S., Nygaard, S. C., and Soderling, T. R. (2004). Inhibition of calcium/calmodulin-dependent protein kinase kinase by protein 14-3-3. J. Biol. Chem. 279, 52191-52199. doi: 10.1074/jbc.M409873200

Edelman, A. M., Mitchelhill, K. I., Selbert, M. A., Anderson, K. A., Hook, S. S., Stapleton, D., et al. (1996). Multiple Ca(2+)-calmodulin-dependent protein kinase kinases from rat brain. Purification, regulation by $\mathrm{Ca}(2+)$ calmodulin, and partial amino acid sequence. J. Biol. Chem. 271, 10806-10810. doi: $10.1074 /$ jbc.271.18.10806

El-Cheikh, J., Devillier, R., Crocchiolo, R., Furst, S., Calmels, B., Faucher, C., et al. (2013). Impact of pretransplant donor and recipient cytomegalovirus serostatus on outcome for multiple myeloma patients undergoing reduced intensity conditioning allogeneic stem cell transplantation. Mediterr. J. Hematol. Infect. Dis. 5:e2013026. doi: 10.4084/mjhid.2013.026

Enslen, H., Sun, P., Brickey, D., Soderling, S. H., Klamo, E., and Soderling, T. R. (1994). Characterization of $\mathrm{Ca}^{2+} /$ calmodulin-dependent protein kinase IV. Role in transcriptional regulation. J. Biol. Chem. 269, 15520-15527.

Enslen, H., Tokumitsu, H., and Soderling, T. R. (1995). Phosphorylation of CREB by CaM-kinase IV activated by CaM-kinase IV kinase. Biochem. Biophys. Res. Commun. 207, 1038-1043. doi: 10.1006/bbrc.1995.1289

Flores-Aguilar, M., Kuppermann, B. D., Quiceno, J. I., Dankner, W. M., Wolf, D. G., Capparelli, E. V., et al. (1993). Pathophysiology and treatment of clinically resistant cytomegalovirus retinitis. Ophthalmology 100, 1022-1031. doi: 10.1016/S0161-6420(93)31523-X 
Foretz, M., Guihard, S., Leclerc, J., Fauveau, V., Couty, J. P., Andris, F., et al. (2010a). Maintenance of red blood cell integrity by AMPactivated protein kinase alphal catalytic subunit. FEBS Lett. 584, 3667-3671. doi: 10.1016/j.febslet.2010.07.041

Foretz, M., Hébrard, S., Leclerc, J., Zarrinpashneh, E., Soty, M., Mithieux, G., et al. (2010b). Metformin inhibits hepatic gluconeogenesis in mice independently of the LKB1/AMPK pathway via a decrease in hepatic energy state. J. Clin. Invest. 120, 2355-2369. doi: 10.1172/JCI40671

Forte, E., Zhang, Z., Thorp, E. B., and Hummel, M. (2020). Cytomegalovirus latency and reactivation: an intricate interplay with the host immune response. Front. Cell. Infect. Microbiol. 10:130. doi: 10.3389/fcimb.2020.00130

Fu, X., Zhao, J. X., Liang, J., Zhu, M. J., Foretz, M., Viollet, B., et al. (2013a). AMP-activated protein kinase mediates myogenin expression and myogenesis via histone deacetylase 5. Am. J. Physiol. Cell Physiol. 305, C887-C895. doi: 10.1152/ajpcell.00124.2013

Fu, X., Zhao, J. X., Zhu, M. J., Foretz, M., Viollet, B., Dodson, M. V., et al. (2013b). AMP-activated protein kinase $\alpha 1$ but not $\alpha 2$ catalytic subunit potentiates myogenin expression and myogenesis. Mol. Cell. Biol. 33, 4517-4525. doi: 10.1128/MCB.01078-13

Fujiwara, Y., Kawaguchi, Y., Fujimoto, T., Kanayama, N., Magari, M., and Tokumitsu, H. (2016). Differential AMP-activated protein kinase (AMPK) recognition mechanism of $\mathrm{Ca}^{2+} /$ Calmodulin-dependent protein kinase kinase isoforms. J. Biol. Chem. 291, 13802-13808. doi: 10.1074/jbc.M116.727867

Gao, J. L., and Murphy, P. M. (1994). Human cytomegalovirus open reading frame US28 encodes a functional beta chemokine receptor. J. Biol. Chem. 269, 28539-28542.

Giese, K. P., Fedorov, N. B., Filipkowski, R. K., and Silva, A. J. (1998). Autophosphorylation at Thr286 of the alpha calcium-calmodulin kinase II in LTP and learning. Science 279, 870-873. doi: 10.1126/science.279.5352.870

Gocher, A. M., Azabdaftari, G., Euscher, L. M., Dai, S., Karacosta, L. G., Franke, T. F., et al. (2017). Akt activation by $\mathrm{Ca}(2+) /$ calmodulin-dependent protein kinase kinase 2 (CaMKK2) in ovarian cancer cells. J. Biol. Chem. 292, 14188-14204. doi: 10.1074/jbc.M117.778464

Goldmacher, V. S., Bartle, L. M., Skaletskaya, A., Dionne, C. A., Kedersha, N. L., Vater, C. A., et al. (1999). A cytomegalovirus-encoded mitochondria-localized inhibitor of apoptosis structurally unrelated to Bcl-2. Proc. Natl. Acad. Sci. U. S. A. 96, 12536-12541. doi: 10.1073/pnas.96.22.12536

Goodrich, J. M., Bowden, R. A., Fisher, L., Keller, C., Schoch, G., and Meyers, J. D. (1993). Ganciclovir prophylaxis to prevent cytomegalovirus disease after allogeneic marrow transplant. Ann. Intern. Med. 118, 173-178. doi: 10.7326/0003-4819-118-3-199302010-00003

Gormand, A., Henriksson, E., Ström, K., Jensen, T. E., Sakamoto, K., and Göransson, O. (2011). Regulation of AMP-activated protein kinase by LKB1 and CaMKK in adipocytes. J. Cell. Biochem. 112, 1364-1375. doi: $10.1002 / j \mathrm{cb} .23053$

Gowans, G. J., Hawley, S. A., Ross, F. A., and Hardie, D. G. (2013). AMP is a true physiological regulator of AMP-activated protein kinase by both allosteric activation and enhancing net phosphorylation. Cell Metab. 18, 556-566. doi: 10.1016/j.cmet.2013.08.019

Green, M. F., Scott, J. W., Steel, R., Oakhill, J. S., Kemp, B. E., and Means, A. R. (2011). $\mathrm{Ca}^{2+} /$ Calmodulin-dependent protein kinase kinase beta is regulated by multisite phosphorylation. J. Biol. Chem. 286, 28066-28079. doi: 10.1074/jbc.M111.251504

Gwinn, D. M., Shackelford, D. B., Egan, D. F., Mihaylova, M. M., Mery, A., Vasquez, D. S., et al. (2008). AMPK phosphorylation of raptor mediates a metabolic checkpoint. Mol. Cell 30, 214-226. doi: 10.1016/j.molcel.2008.03.003

Hahn, G., Jores, R., and Mocarski, E. S. (1998). Cytomegalovirus remains latent in a common precursor of dendritic and myeloid cells. Proc. Natl. Acad. Sci. U. S. A. 95, 3937-3942. doi: 10.1073/pnas.95.7.3937

Hanahan, D., and Weinberg, R. A. (2011). Hallmarks of cancer: the next generation. Cell 144, 646-674. doi: 10.1016/j.cell.2011.02.013

Hardie, D. G., Schaffer, B. E., and Brunet, A. (2016). AMPK: an energy-sensing pathway with multiple inputs and outputs. Trends Cell Biol. 26, 190-201. doi: $10.1016 /$ j.tcb.2015.10.013

Herbein, G. (2018). The human cytomegalovirus, from oncomodulation to oncogenesis. Viruses 10:408. doi: 10.3390/v10080408

Hsich, E., Zhou, Y. F., Paigen, B., Johnson, T. M., Burnett, M. S., and Epstein, S. E. (2001). Cytomegalovirus infection increases development of atherosclerosis in Apolipoprotein-E knockout mice. Atherosclerosis 156, 23-28. doi: 10.1016/S0021-9150(00)00608-0

Hsu, L. S., Chen, G. D., Lee, L. S., Chi, C. W., Cheng, J. F., and Chen, J. Y. (2001). Human $\mathrm{Ca}^{2+} /$ calmodulin-dependent protein kinase kinase beta gene encodes multiple isoforms that display distinct kinase activity. J. Biol. Chem. 276, 31113-31123. doi: 10.1074/jbc.M011720200

Hudmon, A., Schulman, H., Kim, J., Maltez, J. M., Tsien, R. W., and Pitt, G. S. (2005). CaMKII tethers to L-type $\mathrm{Ca}^{2+}$ channels, establishing a local and dedicated integrator of $\mathrm{Ca}^{2+}$ signals for facilitation. J. Cell Biol. 171, 537-547. doi: $10.1083 /$ jcb. 200505155

Jaillette, E., Girault, C., Brunin, G., Zerimech, F., Chiche, A., BroucqsaultDedrie, C., et al. (2016). French intensive care society, International congress - Réanimation 2016. Ann Intensive Care 6(Suppl. 1):50. doi: 10.1186/s13613-016-0114-z

Jeon, S. M., and Hay, N. (2012). The dark face of AMPK as an essential tumor promoter. Cell. Logist. 2, 197-202. doi: 10.4161/cl.22651

Jeon, S. M., and Hay, N. (2015). The double-edged sword of AMPK signaling in cancer and its therapeutic implications. Arch. Pharm. Res. 38, 346-357. doi: 10.1007/s12272-015-0549-z

Jester, B. W., Cox, K. J., Gaj, A., Shomin, C. D., Porter, J. R., and Ghosh, I. (2010). A coiled-coil enabled split-luciferase three-hybrid system: applied toward profiling inhibitors of protein kinases. J. Am. Chem. Soc. 132, 11727-11735. doi: $10.1021 /$ ja104491h

Johnson, J., Rychahou, P., Sviripa, V. M., Weiss, H. L., Liu, C., Watt, D. S., et al. (2019). Induction of AMPK activation by N,N'-diarylurea FND-4b decreases growth and increases apoptosis in triple negative and estrogen-receptor positive breast cancers. PLoS ONE 14:e0209392. doi: 10.1371/journal.pone.0209392

Kalender, A., Selvaraj, A., Kim, S. Y., Gulati, P., Brûlé, S., Viollet, B., et al. (2010). Metformin, independent of AMPK, inhibits mTORC1 in a rag GTPasedependent manner. Cell Metab. 11, 390-401. doi: 10.1016/j.cmet.2010.03.014

Kamata, A., Sakagami, H., Tokumitsu, H., Owada, Y., Fukunaga, K., and Kondo, H. (2007). Spatiotemporal expression of four isoforms of $\mathrm{Ca}^{2+} /$ calmodulindependent protein kinase $\mathrm{I}$ in brain and its possible roles in hippocampal dendritic growth. Neurosci. Res. 57, 86-97. doi: 10.1016/j.neures.2006.09.013

Kamm, K. E., and Stull, J. T. (1985). The function of myosin and myosin light chain kinase phosphorylation in smooth muscle. Annu. Rev. Pharmacol. Toxicol. 25, 593-620. doi: 10.1146/annurev.pa.25.040185.003113

Kaufman, M. R., and Brown, T. L. (2016). AMPK and placental progenitor cells. Exp. Suppl. 107, 73-79. doi: 10.1007/978-3-319-43589-3_4

Kenlan, D. E., Rychahou, P., Sviripa, V. M., Weiss, H. L., Liu, C., Watt, D. S., et al. (2017). Fluorinated N,N'-Diarylureas as novel therapeutic agents against cancer stem cells. Mol. Cancer Ther. 16, 831-837. doi: 10.1158/1535-7163.MCT-15-0634

Kim, J., Kundu, M., Viollet, B., and Guan, K. L. (2011). AMPK and mTOR regulate autophagy through direct phosphorylation of Ulk1. Nat. Cell Biol. 13, 132-141. doi: $10.1038 /$ ncb2152

Kishimoto, A., Takai, Y., and Nishizuka, Y. (1977). Activation of glycogen phosphorylase kinase by a calcium-activated, cyclic nucleotide-independent protein kinase system. J. Biol. Chem. 252, 7449-7452.

Kitsos, C. M., Sankar, U., Illario, M., Colomer-Font, J. M., Duncan, A. W., Ribar, T. J., et al. (2005). Calmodulin-dependent protein kinase IV regulates hematopoietic stem cell maintenance. J. Biol. Chem. 280, 33101-33108. doi: 10.1074/jbc.M505208200

Kudchodkar, S. B., Del Prete, G. Q., Maguire, T. G., and Alwine, J. C. (2007). AMPK-mediated inhibition of mTOR kinase is circumvented during immediate-early times of human cytomegalovirus infection. J. Virol. 81, 3649-3651. doi: 10.1128/JVI.02079-06

Kuo, C. P., Wu, C. L., Ho, H. T., Chen, C. G., Liu, S. I., and Lu, Y. T. (2008). Detection of cytomegalovirus reactivation in cancer patients receiving chemotherapy. Clin. Microbiol. Infect. 14, 221-227. doi: 10.1111/j.1469-0691.2007.01895.x

Kurth-Kraczek, E. J., Hirshman, M. F., Goodyear, L. J., and Winder, W. W. (1999). 5 ' AMP-activated protein kinase activation causes GLUT4 translocation in skeletal muscle. Diabetes 48, 1667-1671. doi: 10.2337/diabetes.48.8.1667

Laderoute, K. R., Amin, K., Calaoagan, J. M., Knapp, M., Le, T., Orduna, J., et al. (2006). 5'-AMP-activated protein kinase (AMPK) is induced by low-oxygen and glucose deprivation conditions found in solid-tumor microenvironments. Mol. Cell. Biol. 26, 5336-5347. doi: 10.1128/MCB.00166-06 
Lee, H., Zandkarimi, F., Zhang, Y., Meena, J. K., Kim, J., Zhuang, L., et al. (2020). Energy-stress-mediated AMPK activation inhibits ferroptosis. Nat. Cell Biol. 22, 225-234. doi: 10.1038/s41556-020-0461-8

Lee, J. C., and Edelman, A. M. (1994). A protein activator of $\mathrm{Ca}(2+)$-calmodulindependent protein kinase Ia. J. Biol. Chem. 269, 2158-2164.

Li, H., Ning, X., Liu, H., Chen, Y., Ding, X., Zhang, H., et al. (2017). Metformin suppressed human cytomegalovirus (hCMV) replication and its potential molecular mechanisms in human fibroblasts. J. Immunol. 198(1 Suppl.), 158.123.

Liu, W., Xu, C., Ran, D., Wang, Y., Zhao, H., Gu, J., et al. (2018). CaMKII mediates cadmium induced apoptosis in rat primary osteoblasts through MAPK activation and endoplasmic reticulum stress. Toxicology 406-407, 70-80. doi: 10.1016/j.tox.2018.06.002

Luganini, A., Di Nardo, G., Munaron, L., Gilardi, G., Fiorio Pla, A., and Gribaudo, G. (2018). Human cytomegalovirus US21 protein is a viroporin that modulates calcium homeostasis and protects cells against apoptosis. Proc. Natl. Acad. Sci U. S. A. 115, E12370-E12377. doi: 10.1073/pnas.1813183115

Maier, L. S., and Bers, D. M. (2007). Role of $\mathrm{Ca}^{2+} /$ calmodulin-dependent protein kinase (CaMK) in excitation-contraction coupling in the heart. Cardiovasc. Res. 73, 631-640. doi: 10.1016/j.cardiores.2006.11.005

Marsin, A. S., Bertrand, L., Rider, M. H., Deprez, J., Beauloye, C., Vincent, M. F., et al. (2000). Phosphorylation and activation of heart PFK-2 by AMPK has a role in the stimulation of glycolysis during ischaemia. Curr. Biol. 10, 1247-1255. doi: 10.1016/S0960-9822(00)00742-9

Matsumoto, Y., and Maller, J. L. (2002). Calcium, calmodulin, and CaMKII requirement for initiation of centrosome duplication in Xenopus egg extracts. Science 295, 499-502. doi: 10.1126/science.1065693

Matsushita, M., and Nairn, A. C. (1999). Inhibition of the $\mathrm{Ca}^{2+} /$ calmodulindependent protein kinase I cascade by cAMP-dependent protein kinase. J. Biol. Chem. 274, 10086-10093. doi: 10.1074/jbc.274.15.10086

Maussang, D., Langemeijer, E., Fitzsimons, C. P., Stigter-van Walsum, M., Dijkman, R., Borg, M. K., et al. (2009). The human cytomegalovirusencoded chemokine receptor US28 promotes angiogenesis and tumor formation via cyclooxygenase-2. Cancer Res. 69, 2861-2869. doi: 10.1158/0008-5472.CAN-08-2487

McArdle, J., Moorman, N. J., and Munger, J. (2012). HCMV targets the metabolic stress response through activation of AMPK whose activity is important for viral replication. PLoS Pathog. 8:e1002502. doi: 10.1371/journal.ppat.1002502

McArdle, J., Schafer, X. L., and Munger, J. (2011). Inhibition of calmodulindependent kinase kinase blocks human cytomegalovirus-induced glycolytic activation and severely attenuates production of viral progeny. J. Virol. 85, 705-714. doi: 10.1128/JVI.01557-10

McCormick, A. L., Smith, V. L., Chow, D., and Mocarski, E. S. (2003). Disruption of mitochondrial networks by the human cytomegalovirus UL37 gene product viral mitochondrion-localized inhibitor of apoptosis. J. Virol. 77, 631-641. doi: 10.1128/JVI.77.1.631-641.2003

McGee, S. L., van Denderen, B. J., Howlett, K. F., Mollica, J., Schertzer, J. D., Kemp, B. E., et al. (2008). AMP-activated protein kinase regulates GLUT4 transcription by phosphorylating histone deacetylase 5. Diabetes 57, 860-867. doi: $10.2337 / \mathrm{db} 07-0843$

Melander Gradin, H., Marklund, U., Larsson, N., Chatila, T. A., and Gullberg, M. (1997). Regulation of microtubule dynamics by $\mathrm{Ca}^{2+} /$ calmodulin-dependent kinase IV/Gr-dependent phosphorylation of oncoprotein 18. Mol. Cell. Biol. 17, 3459-3467. doi: 10.1128/MCB.17.6.3459

Michaelis, M., Doerr, H. W., and Cinatl, J. (2009). The story of human cytomegalovirus and cancer: increasing evidence and open questions. Neoplasia 11, 1-9. doi: 10.1593/neo.81178

Miller, W. E., Zagorski, W. A., Brenneman, J. D., Avery, D., Miller, J. L., and O'Connor, C. M. (2012). US28 is a potent activator of phospholipase C during HCMV infection of clinically relevant target cells. PLOS ONE 7:e50524. doi: 10.1371/journal.pone.0050524

Mobbs, J. I., Koay, A., Di Paolo, A., Bieri, M., Petrie, E. J., Gorman, M. A., et al. (2015). Determinants of oligosaccharide specificity of the carbohydratebinding modules of AMP-activated protein kinase. Biochem. J. 468, 245-257. doi: 10.1042/BJ20150270

Mochida, S., Kobayashi, H., Matsuda, Y., Yuda, Y., Muramoto, K., and Nonomura, Y. (1994). Myosin II is involved in transmitter release at synapses formed between rat sympathetic neurons in culture. Neuron 13, 1131-1142. doi: 10.1016/0896-6273(94)90051-5

Mones, S., Bordignon, B., Peiretti, F., Landrier, J. F., Gess, B., Bourguignon, J. J., et al. (2014). CamKII inhibitors reduce mitotic instability, connexon anomalies and progression of the in vivo behavioral phenotype in transgenic animals expressing a mutated Gjb1 gene. Front. Neurosci. 8:151. doi: 10.3389/fnins.2014.00151

Monteverde, T., Muthalagu, N., Port, J., and Murphy, D. J. (2015). Evidence of cancer-promoting roles for AMPK and related kinases. FEBS J. 282, 4658-4671. doi: $10.1111 /$ febs. 13534

Murray, M. J., Peters, N. E., and Reeves, M. B. (2018). Navigating the host cell response during entry into sites of latent cytomegalovirus infection. Pathogens 7:30. doi: 10.3390/pathogens7010030

Nairn, A. C., and Greengard, P. (1987). Purification and characterization of $\mathrm{Ca}^{2+} /$ calmodulin-dependent protein kinase I from bovine brain. J. Biol. Chem. 262, 7273-7281.

Nairn, A. C., and Palfrey, H. C. (1987). Identification of the major Mr 100,000 substrate for calmodulin-dependent protein kinase III in mammalian cells as elongation factor-2. J. Biol. Chem. 262, 17299-17303.

Nakano, A., Kato, H., Watanabe, T., Min, K. D., Yamazaki, S., Asano, Y., et al. (2010). AMPK controls the speed of microtubule polymerization and directional cell migration through CLIP-170 phosphorylation. Nat. Cell Biol. 12, 583-590. doi: 10.1038/ncb2060

Nauclér, C. S., Geisler, J., and Vetvik, K. (2019). The emerging role of human cytomegalovirus infection in human carcinogenesis: a review of current evidence and potential therapeutic implications. Oncotarget 10, 4333-4347. doi: 10.18632/oncotarget.27016

Nguyen, Q., Estey, E., Raad, I., Rolston, K., Kantarjian, H., Jacobson, K., et al. (2001). Cytomegalovirus pneumonia in adults with leukemia: an emerging problem. Clin. Infect. Dis. 32, 539-545. doi: 10.1086/318721

O'Connor, C. M., and Murphy, E. A. (2012). A myeloid progenitor cell line capable of supporting human cytomegalovirus latency and reactivation, resulting in infectious progeny. J. Virol. 86, 9854-9865. doi: 10.1128/JVI.01278-12

Ohmstede, C. A., Jensen, K. F., and Sahyoun, N. E. (1989). Ca ${ }^{2+} /$ calmodulindependent protein kinase enriched in cerebellar granule cells. Identification of a novel neuronal calmodulin-dependent protein kinase. J. Biol. Chem. 264, 5866-5875.

Ouimet, C. C., McGuinness, T. L., and Greengard, P. (1984). Immunocytochemical localization of calcium/calmodulin-dependent protein kinase II in rat brain. Proc. Natl. Acad. Sci. U. S. A. 81, 5604-5608. doi: 10.1073/pnas.81.17.5604

Owen, M. R., Doran, E., and Halestrap, A. P. (2000). Evidence that metformin exerts its anti-diabetic effects through inhibition of complex 1 of the mitochondrial respiratory chain. Biochem. J. 348, 607-614. doi: 10.1042/bj3480607

Park, S. H., Gammon, S. R., Knippers, J. D., Paulsen, S. R., Rubink, D. S., and Winder, W. W. (2002). Phosphorylation-activity relationships of AMPK and acetyl-CoA carboxylase in muscle. J. Appl. Physiol. 92, 2475-2482. doi: 10.1152/japplphysiol.00071.2002

Pass, R. F. (2001). "Cytomegalovirus," in Fields' Virology, 4th Edn. eds D. M. Knipe and P. M. Howley (New York, NY: Lippincott-Williams and Wilkins), 2675-2705.

Penfold, L., Woods, A., Muckett, P., Nikitin, A. Y., Kent, T. R., Zhang, S., et al. (2018). CAMKK2 promotes prostate cancer independently of AMPK via increased lipogenesis. Cancer Res. 78, 6747-6761. doi: 10.1158/0008-5472.CAN-18-0585

Penfold, M. E. T., Dairaghi, D. J., Duke, G. M., Saederup, N., Mocarski, E. S., Kemble, G. W., et al. (1999). Cytomegalovirus encodes a potent $\alpha$ chemokine. Proc. Natl. Acad. Sci U. S. A. 96, 9839-9844. doi: 10.1073/pnas.96.17.9839

Phoenix, K. N., Devarakonda, C. V., Fox, M. M., Stevens, L. E., and Claffey, K. P. (2012). AMPK $\alpha 2$ suppresses murine embryonic fibroblast transformation and tumorigenesis. Genes Cancer 3, 51-62. doi: 10.1177/1947601912452883

Picciotto, M. R., Zoli, M., Bertuzzi, G., and Nairn, A. C. (1995). Immunochemical localization of calcium/calmodulin-dependent protein kinase I. Synapse 20, 75-84. doi: 10.1002/syn.890200111

Picton, C., Klee, C. B., and Cohen, P. (1981). The regulation of muscle phosphorylase kinase by calcium ions, calmodulin and troponin-C. Cell Calcium 2, 281-294. doi: 10.1016/0143-4160(81)90021-X 
Pinter, K., Grignani, R. T., Watkins, H., and Redwood, C. (2013). Localisation of AMPK $\gamma$ subunits in cardiac and skeletal muscles. J. Muscle Res. Cell Motil. 34, 369-378. doi: 10.1007/s10974-013-9359-4

Pleskoff, O., Casarosa, P., Verneuil, L., Ainoun, F., Beisser, P., Smit, M., et al. (2005). The human cytomegalovirus-encoded chemokine receptor US28 induces caspase-dependent apoptosis. FEBS J. 272, 4163-4177. doi: 10.1111/j.1742-4658.2005.04829.x

Poncet, D., Larochette, N., Pauleau, A. L., Boya, P., Jalil, A. A., Cartron, P. F., et al. (2004). An anti-apoptotic viral protein that recruits Bax to mitochondria. J. Biol. Chem. 279, 22605-22614. doi: 10.1074/jbc.M308408200

Potena, L., Frascaroli, G., Grigioni, F., Lazzarotto, T., Magnani, G., Tomasi, L., et al. (2004). Hydroxymethyl-glutaryl coenzyme a reductase inhibition limits cytomegalovirus infection in human endothelial cells. Circulation 109, 532-536. doi: 10.1161/01.CIR.0000109485.79183.81

Rådestad, A. F., Estekizadeh, A., Cui, H. L., Kostopoulou, O. N., Davoudi, B., Hirschberg, A. L., et al. (2018). Impact of human cytomegalovirus infection and its immune response on survival of patients with ovarian cancer. Transl. Oncol. 11, 1292-1300. doi: 10.1016/j.tranon.2018.08.003

Racioppi, L., and Means, A. R. (2008). Calcium/calmodulin-dependent kinase IV in immune and inflammatory responses: novel routes for an ancient traveller. Trends Immunol. 29, 600-607. doi: 10.1016/j.it.2008.08.005

Rahman, M., Dastmalchi, F., Karachi, A., and Mitchell, D. (2019). The role of CMV in glioblastoma and implications for immunotherapeutic strategies. Oncoimmunology 8:e1514921. doi: 10.1080/2162402X.2018.1514921

Ranganathan, P., Clark, P. A., Kuo, J. S., Salamat, M. S., and Kalejta, R. F. (2012). Significant association of multiple human cytomegalovirus genomic Loci with glioblastoma multiforme samples. J. Virol. 86, 854-864. doi: 10.1128/JVI.06097-11

Rodríguez-Sánchez, I., Schafer, X. L., Monaghan, M., and Munger, J. (2019). The Human Cytomegalovirus UL38 protein drives mTOR-independent metabolic flux reprogramming by inhibiting TSC2. PLoS Pathog. 15:e1007569. doi: 10.1371/journal.ppat.1007569

Ross, F. A., Jensen, T. E., and Hardie, D. G. (2016a). Differential regulation by AMP and ADP of AMPK complexes containing different $\gamma$ subunit isoforms. Biochem. J. 473, 189-199. doi: 10.1042/BJ20150910

Ross, F. A., MacKintosh, C., and Hardie, D. G. (2016b). AMP-activated protein kinase: a cellular energy sensor that comes in 12 flavours. FEBS J. 283, 2987-3001. doi: 10.1111/febs.13698

Rostas, J. A., Hoffman, A., Murtha, L. A., Pepperall, D., McLeod, D. D., Dickson, P. W., et al. (2017). Ischaemia- and excitotoxicity-induced CaMKII-Mediated neuronal cell death: the relative roles of CaMKII autophosphorylation at T286 and T253. Neurochem. Int. 104, 6-10. doi: 10.1016/j.neuint.2017. 01.002

Schmitt, J. M., Guire, E. S., Saneyoshi, T., and Soderling, T. R. (2005). Calmodulindependent kinase kinase/calmodulin kinase I activity gates extracellularregulated kinase-dependent long-term potentiation. J. Neurosci. 25, 1281-1290. doi: 10.1523/JNEUROSCI.4086-04.2005

Schmitt, J. M., Wayman, G. A., Nozaki, N., and Soderling, T. R. (2004). Calcium activation of ERK mediated by calmodulin kinase I. J. Biol. Chem. 279, 24064-24072. doi: 10.1074/jbc.M401501200

Schottstedt, V., Blümel, J., Burger, R., Drosten, C., Gröner, A., Gürtler, L., et al. (2010). Human cytomegalovirus (HCMV) - revised. Transfus. Med. Hemother. 37, 365-375. doi: 10.1159/000322141

Schumacher, A. M., Schavocky, J. P., Velentza, A. V., Mirzoeva, S., and Watterson, D. M. (2004). A calmodulin-regulated protein kinase linked to neuron survival is a substrate for the calmodulin-regulated death-associated protein kinase. Biochemistry 43, 8116-8124. doi: 10.1021/bi049589v

Senga, Y., Ishida, A., Shigeri, Y., Kameshita, I., and Sueyoshi, N. (2015). The phosphatase-resistant isoform of CaMKI, $\mathrm{Ca}^{2}+/$ Calmodulin-dependent protein kinase I $\delta$ (CaMKI $\delta$ ), remains in its "Primed" form without $\mathrm{Ca}^{2}+$ stimulation. Biochemistry 54, 3617-3630. doi: 10.1021/bi5012139

Shackelford, D. B., and Shaw, R. J. (2009). The LKB1-AMPK pathway: metabolism and growth control in tumour suppression. Nat. Rev. Cancer 9, 563-575. doi: $10.1038 / \mathrm{nrc} 2676$

Sharon-Friling, R., Goodhouse, J., Colberg-Poley, A. M., and Shenk, T. (2006). Human cytomegalovirus pUL37x1 induces the release of endoplasmic reticulum calcium stores. Proc. Natl. Acad. Sci. U. S. A. 103, 19117-19122. doi: $10.1073 /$ pnas.0609353103
Sheng, M., Thompson, M. A., and Greenberg, M. E. (1991). CREB: a Ca(2+)regulated transcription factor phosphorylated by calmodulin-dependent kinases. Science 252, 1427-1430. doi: 10.1126/science.1646483

Shenk, T., and Alwine, J. C. (2014). Human cytomegalovirus: coordinating cellular stress, signaling, and metabolic pathways. Annu. Rev. Virol. 1, 355-374. doi: 10.1146/annurev-virology-031413-085425

Shin, M. K., Kim, M. K., Bae, Y. S., Jo, I., Lee, S. J., Chung, C. P., et al. (2008). A novel collagen-binding peptide promotes osteogenic differentiation via $\mathrm{Ca}^{2+} /$ calmodulin-dependent protein kinase II/ERK/AP-1 signaling pathway in human bone marrow-derived mesenchymal stem cells. Cell. Signal. 20, 613-624. doi: 10.1016/j.cellsig.2007.11.012

Sison, S. L., O’Brien, B. S., Johnson, A. J., Seminary, E. R., Terhune, S. S., and Ebert, A. D. (2019). Human cytomegalovirus disruption of calcium signaling in neural progenitor cells and organoids. J. Virol. 93, 1-23. doi: 10.1128/JVI.00954-19

Skelding, K. A., Rostas, J. A., and Verrills, N. M. (2011). Controlling the cell cycle: the role of calcium/calmodulin-stimulated protein kinases I and II. Cell Cycle 10, 631-639. doi: 10.4161/cc.10.4.14798

Slinger, E., Maussang, D., Schreiber, A., Siderius, M., Rahbar, A., FraileRamos, A., et al. (2010). HCMV-encoded chemokine receptor US28 mediates proliferative signaling through the IL-6-STAT3 axis. Sci. Signal 3:ra58. doi: $10.1126 /$ scisignal. 2001180

Soderling, T. R., and Stull, J. T. (2001). Structure and regulation of calcium/calmodulin-dependent protein kinases. Chem. Rev. 101, 2341-2352. doi: $10.1021 / \mathrm{cr} 0002386$

Soroceanu, L., Matlaf, L., Bezrookove, V., Harkins, L., Martinez, R., Greene, M., et al. (2011). Human cytomegalovirus US28 found in glioblastoma promotes an invasive and angiogenic phenotype. Cancer Res. 71, 6643-6653. doi: 10.1158/0008-5472.CAN-11-0744

Spencer, C. M., Schafer, X. L., Moorman, N. J., and Munger, J. (2011). Human cytomegalovirus induces the activity and expression of acetyl-coenzyme a carboxylase, a Fatty Acid biosynthetic enzyme whose inhibition attenuates viral replication. J. Virol. 85, 5814-5824. doi: 10.1128/JVI.02630-10

Stapleton, D., Mitchelhill, K. I., Gao, G., Widmer, J., Michell, B. J., Teh, T., et al. (1996). Mammalian AMP-activated protein kinase subfamily. J. Biol. Chem. 271, 611-614. doi: 10.1074/jbc.271.2.611

Stern-Ginossar, N., Weisburd, B., Michalski, A., Le, V. T., Hein, M. Y., Huang S. X., et al. (2012). Decoding human cytomegalovirus. Science 338, 1088-1093. doi: 10.1126/science.1227919

Swanson, E. C., and Schleiss, M. R. (2013). Congenital cytomegalovirus infection: new prospects for prevention and therapy. Pediatr. Clin. North Am. 60, 335-349. doi: 10.1016/j.pcl.2012.12.008

Swulius, M. T., and Waxham, M. N. (2008). Ca(2+)/calmodulindependent protein kinases. Cell. Mol. Life Sci. 65, 2637-2657. doi: $10.1007 / \mathrm{s} 00018-008-8086-2$

Taher, C., de Boniface, J., Mohammad, A. A., Religa, P., Hartman, J., Yaiw, K. C. et al. (2013). High prevalence of human cytomegalovirus proteins and nucleic acids in primary breast cancer and metastatic sentinel lymph nodes. PLoS ONE 8:e56795. doi: 10.1371/journal.pone.0056795

Taher, C., Frisk, G., Fuentes, S., Religa, P., Costa, H., Assinger, A., et al. (2014). High prevalence of human cytomegalovirus in brain metastases of patients with primary breast and colorectal cancers. Transl. Oncol. 7, 732-740. doi: 10.1016/j.tranon.2014.09.008

Takamori, S., Holt, M., Stenius, K., Lemke, E. A., Grønborg, M., Riedel, D., et al. (2006). Molecular anatomy of a trafficking organelle. Cell 127, 831-846. doi: 10.1016/j.cell.2006.10.030

Tay, M. R., Lim, S. T., Tao, M., Quek, R. H., Tay, K., and Tan, T. T. (2013). Cytomegalovirus infection and end-organ disease in Asian patients with lymphoma receiving chemotherapy. Leuk. Lymphoma. doi: 10.3109/10428194.2013.798867

Teh, B. W., Khot, A. S., Harrison, S. J., Prince, H. M., and Slavin, M. A. (2013). A messenger at the door: cytomegalovirus retinitis in myeloma patients with progressive disease. Transpl. Infect. Dis. 15, E134-E138. doi: 10.1111/tid.12106

Terry, L. J., Vastag, L., Rabinowitz, J. D., and Shenk, T. (2012). Human kinome profiling identifies a requirement for AMP-activated protein kinase during human cytomegalovirus infection. Proc. Natl. Acad. Sci. U. S. A. 109, 3071-3076. doi: 10.1073/pnas.1200494109

Tokumitsu, H., Brickey, D. A., Glod, J., Hidaka, H., Sikela, J., and Soderling, T. R. (1994). Activation mechanisms for $\mathrm{Ca}^{2+} /$ calmodulin-dependent protein 
kinase IV. Identification of a brain CaM-kinase IV kinase. J. Biol. Chem. 269, 28640-28647.

Tokumitsu, H., Enslen, H., and Soderling, T. R. (1995). Characterization of a $\mathrm{Ca}^{2+} /$ calmodulin-dependent protein kinase cascade. Molecular cloning and expression of calcium/calmodulin-dependent protein kinase kinase. J. Biol. Chem. 270, 19320-19324. doi: 10.1074/jbc.270.33.19320

Tokumitsu, H., Hatano, N., Fujimoto, T., Yurimoto, S., and Kobayashi, R. (2011). Generation of autonomous activity of $\mathrm{Ca}(2+) /$ calmodulin-dependent protein kinase kinase $\beta$ by autophosphorylation. Biochemistry 50, 8193-8201. doi: $10.1021 / \mathrm{bi2} 201005 \mathrm{~g}$

Tokumitsu, H., Iwabu, M., Ishikawa, Y., and Kobayashi, R. (2001). Differential regulatory mechanism of $\mathrm{Ca}^{2+} /$ calmodulin-dependent protein kinase kinase isoforms. Biochemistry 40, 13925-13932. doi: 10.1021/bi010863k

Uhlén, M., Fagerberg, L., Hallström, B. M., Lindskog, C., Oksvold, P., Mardinoglu, A., et al. (2015). Proteomics. Tissue-based map of the human proteome. Science 347:1260419. doi: 10.1126/science. 1260419

Vara-Ciruelos, D., Dandapani, M., Gray, A., Egbani, E. O., Evans, A. M., and Hardie, D. G. (2018). Genotoxic damage activates the AMPK- $\alpha 1$ isoform in the nucleus via $\mathrm{Ca}(2+) / \mathrm{CaMKK} 2$ signaling to enhance tumor cell survival. Mol. Cancer Res. 16, 345-357. doi: 10.1158/1541-7786.MCR-17-0323

Vieira, J., Schall, T. J., Corey, L., and Geballe, A. P. (1998). Functional analysis of the human cytomegalovirus US28 gene by insertion mutagenesis with the green fluorescent protein gene. J. Virol. 72, 8158-8165. doi: 10.1128/JVI.72.10.8158-8165.1998

Viollet, B., Andreelli, F., Jørgensen, S. B., Perrin, C., Geloen, A., Flamez, D., et al. (2003). The AMP-activated protein kinase alpha2 catalytic subunit controls whole-body insulin sensitivity. J. Clin. Invest. 111, 91-98. doi: 10.1172/JCI16567

Viollet, B., Athea, Y., Mounier, R., Guigas, B., Zarrinpashneh, E., Horman, S., et al. (2009). AMPK: lessons from transgenic and knockout animals. Front. Biosci. 14, 19-44. doi: 10.2741/3229

Wang, X., Huong, S. M., Chiu, M. L., Raab-Traub, N., and Huang, E. S. (2003). Epidermal growth factor receptor is a cellular receptor for human cytomegalovirus. Nature 424, 456-461. doi: 10.1038/nature01818

Wang, Y. C., Wang, N. C., Lin, J. C., Perng, C. L., Yeh, K. M., Yang, Y. S., et al. (2011). Risk factors and outcomes of cytomegalovirus viremia in cancer patients: a study from a medical center in northern Taiwan. J. Microbiol. Immunol. Infect. 44, 442-448. doi: 10.1016/j.jmii.2011.04.004

Wang, Y. G., Han, X. G., Yang, Y., Qiao, H., Dai, K. R., Fan, Q. M., et al. (2016). Functional differences between AMPK $\alpha 1$ and $\alpha 2$ subunits in osteogenesis, osteoblast-associated induction of osteoclastogenesis, and adipogenesis. Sci. Rep. 6:32771. doi: 10.1038/srep32771

Wang, Z. W. (2008). Regulation of synaptic transmission by presynaptic CaMKII and BK channels. Mol. Neurobiol. 38, 153-166. doi: 10.1007/s12035-008-8039-7

Wei, F., Qiu, C. S., Liauw, J., Robinson, D. A., Ho, N., Chatila, T., et al. (2002). Calcium calmodulin-dependent protein kinase IV is required for fear memory. Nat. Neurosci. 5, 573-579. doi: 10.1038/nn0602-855
Weisenthal, R. W., Sinclair, S. H., Frank, I., and Rubin, D. H. (1989). Long-term outpatient treatment of CMV retinitis with ganciclovir in AIDS patients. Br. J. Ophthalmol. 73, 996-1001. doi: 10.1136/bjo.73. 12.996

Williams, T., Courchet, J., Viollet, B., Brenman, J. E., and Polleux, F. (2011). AMP-activated protein kinase (AMPK) activity is not required for neuronal development but regulates axogenesis during metabolic stress. Proc. Natl. Acad. Sci. U. S. A. 108, 5849-5854. doi: 10.1073/pnas. 1013660108

Willows, R., Navaratnam, N., Lima, A., Read, J., and Carling, D. (2017). Effect of different gamma-subunit isoforms on the regulation of AMPK. Biochem. J. 474, 1741-1754. doi: 10.1042/BCJ20170046

Woods, A., Dickerson, K., Heath, R., Hong, S. P., Momcilovic, M., Johnstone, S. R., et al. (2005). $\mathrm{Ca}^{2+} /$ calmodulin-dependent protein kinase kinase-beta acts upstream of AMP-activated protein kinase in mammalian cells. Cell Metab. 2, 21-33. doi: 10.1016/j.cmet.2005.06.005

Woods, A., Johnstone, S. R., Dickerson, K., Leiper, F. C., Fryer, L. G., Neumann, D., et al. (2003). LKB1 is the upstream kinase in the AMP-activated protein kinase cascade. Curr. Biol. 13, 2004-2008. doi: 10.1016/j.cub.2003. 10.031

Word, R. A., Tang, D. C., and Kamm, K. E. (1994). Activation properties of myosin light chain kinase during contraction/relaxation cycles of tonic and phasic smooth muscles. J. Biol. Chem. 269, 21596-21602.

Yan, X., Liu, J., Ye, Z., Huang, J., He, F., Xiao, W., et al. (2016). CaMKIImediated CREB phosphorylation is involved in $\mathrm{Ca}^{2+}$-induced BDNF mRNA transcription and neurite outgrowth promoted by electrical stimulation. PLoS ONE 11:e0162784. doi: 10.1371/journal.pone.0162784

Yano, S., Tokumitsu, H., and Soderling, T. R. (1998). Calcium promotes cell survival through CaM-K kinase activation of the protein-kinase-B pathway. Nature 396, 584-587. doi: 10.1038/25147

Yu, Y., Maguire, T. G., and Alwine, J. C. (2011). Human cytomegalovirus activates glucose transporter 4 expression to increase glucose uptake during infection. $J$. Virol. 85, 1573-1580. doi: 10.1128/JVI.01967-10

Zapatka, M., Borozan, I., Brewer, D. S., Iskar, M., Grundhoff, A., Alawi, M., et al. (2020). The landscape of viral associations in human cancers. Nat. Genet. 52, 320-330. doi: 10.1038/s41588-019-0558-9

Conflict of Interest: The authors declare that the research was conducted in the absence of any commercial or financial relationships that could be construed as a potential conflict of interest.

Copyright $\odot 2020$ Dunn and Munger. This is an open-access article distributed under the terms of the Creative Commons Attribution License (CC BY). The use, distribution or reproduction in other forums is permitted, provided the original author(s) and the copyright owner(s) are credited and that the original publication in this journal is cited, in accordance with accepted academic practice. No use, distribution or reproduction is permitted which does not comply with these terms. 